\title{
Sinais clínicos, distribuição das lesões no sistema nervoso e epidemiologia da raiva em herbívoros na região Nordeste do Brasil ${ }^{1}$
}

\author{
Everton Ferreira Lima ${ }^{2}$, Franklin Riet-Correa ${ }^{3 *}$, Roberto Soares de Castro ${ }^{4}$, Albério \\ Antonio Barros Gomes ${ }^{5}$ e Fabiano de Sousa Lima ${ }^{6}$
}

\begin{abstract}
Lima E.F., Riet-Correa F., Castro R.S., Gomes A.A.B. \& Lima F.S. 2006. [Clinical signs, distribution of the lesions in the central nervous system and epidemiology of rabies in northeastern Brazil.] Sinais clínicos, distribuição das lesões no sistema nervoso e epidemiologia da raiva em herbívoros na região Nordeste do Brasil. Pesquisa Veterinária Brasileira 25(4):250-264. Centro de Saúde e Tecnologia Rural, Campus de Patos, Universidade Federal de Campina Grande,
\end{abstract} Patos, PB 58700-000, Brazil. E-mail: riet@cstr.ufcg.br

Twenty four outbreaks of rabies in cattle, 4 in horses, 2 in sheep, and 2 in goats are reported in northeastern Brazil. All outbreaks occurred in the state of Paraíba, except one in horses that occurred in the state of Rio Grande do Norte. All outbreaks, except one in sheep, were probably transmitted by vampire-bats, but the transmission by foxes (Dusicyon vetulus) is also possible. Clinical signs were characteristic for distribution of the lesions in the central nervous system (CNS). In cattle, signs were mainly of the paralytic form of rabies, caused by lesions on the spinal cord, brain stem and cerebellum; but some animals showed also depression, excitation and other signs due to cerebral lesions. In 3 out of 5 horses, the main clinical signs were due to lesions in the cerebrum, and 2 had the paralytic form. From 4 sheep and 2 goats affected, 4 showed clinical signs of the paralytic form; but in 1 goat and 1 sheep the main clinical signs were caused by cerebral lesions. All affected animals, except 1 goat, had a clinical manifestation period of 2-8 days. The only gross lesions were distention of the urinary bladder in 4 cattle and distention of the rectum in 2 others. Two horses had skin lesions due to traumatic injury. Histologic lesions were diffuse non-suppurative encephalomyelitis and meningitis. In the horses, and in one goat with a clinical manifestation period of 35 days, the lesions were more severe, with neuronal necrosis, neuronophagia, and presence of axonal spheroids. Negri bodies were found in $87 \%$ (20/23) of the cattle cases examined histologically. In small ruminants Negri bodies were found in $83 \%(5 / 6)$ of the cases. In sheep, goats and cattle, Negri bodies were more frequent in the cerebellum, but they were found also in brain stem, spinal cord and cerebrum. In horses, Negri bodies were found in small amounts only in the cortex of one animal, and in the cortex and hippocampus of another. Histologic lesions and Negri bodies in the trigeminal ganglia were less frequent than in the CNS. These results show that in rabies of herbivores, clinical signs and distribution of lesions in the CNS are variable, so that for the diagnosis and adequate clinical evaluation and the histologic study of different areas of the CNS are necessary. This also suggests that when the fluorescent antibody test and mouse inoculation test are negative, they should be repeated with samples from different areas of the brain and spinal cord. Frequency data of diseases from 4 diagnostic laboratories were used to estimate cattle deaths due to rabies in 3 Brazilian states. In Paraíba, with a population of 918,262 cattle, the annual

\footnotetext{
${ }^{1}$ Recebido em 12 de agosto de 2005.

Aceito para publicação em 28 de outubro de 2005.

2 Pós-Graduando em Ciência Veterinária, Universidade Federal Rural de Pernambuco (UFRPE), Av. D. Manoel de Medeiros s/n, Dois Irmãos, Recife, PE 52171-900.

${ }^{3}$ Curso de Medicina Veterinária da Universidade Federal de Campina
}

Grande (UFCG), Centro de Saúde e Tecnologia Rural, Campus de Patos, 58700-000 Patos, PB. *Autor para correspondência. E-mail: riet@cstr.ufcg.br

${ }^{4}$ Curso de Medicina Veterinária, UFRPE.

${ }^{5}$ Centro de Saúde e Tecnologia Rural (CSTR), UFCG, Campus de Patos, PB.

${ }^{6}$ Pós-Graduando em Medicina Veterinária de Pequenos Ruminantes, CSTR, UFCG, Campus de Patos, PB. 
death rate is estimated in 8,609 heads. In Mato Grosso do Sul, with a population of 23 millions cattle, deaths caused by rabies are estimated in 149,500 heads, and in Rio Grande do Sul, with a cattle population of 13 millions, cattle deaths due to rabies are estimated in 13,000 to 16,250 heads. If these data are used to estimate cattle losses in Brazil, with a cattle population of 195 millions, it can be estimated that 842,688 deaths are caused annually by rabies.

INDEX TERMS: Rabies, cattle, sheep, goats, horses, pathology, clinical signs, economical impact.

RESUMO.- Descrevem-se 24 surtos de raiva em bovinos (25 casos), 4 em eqüinos (5 casos), 2 em caprinos (2 casos) e 2 em ovinos (4 casos). Todos os surtos ocorreram na Paraíba, exceto um em eqüinos que ocorreu no Rio Grande do Norte. Todos os surtos, com a exceção de um em ovinos, foram transmitidos provavelmente por morcegos hematófagos; no entanto, não se descarta a possibilidade de transmissão por raposas (Dusicyon vetulus). Os sinais clínicos foram representativos da localização das lesões no sistema nervoso central (SNC). Em bovinos os sinais eram, principalmente, da forma paralítica, causados por lesões da medula, tronco encefálico e cerebelo; mas alguns animais apresentaram depressão, excitação e outros sinais associados a lesões cerebrais. Três dos 5 eqüinos apresentaram sinais de lesões cerebrais e 2 apresentaram a forma paralítica. De 4 ovinos e 2 caprinos, 4 apresentaram a forma paralítica, mas em um caprino e um ovino os sinais foram predominantemente de lesões cerebrais. Todos os animais afetados, exceto um caprino, tiveram um curso clínico de 2-8 dias. As únicas lesões macroscópicas observadas foram a dilatação da bexiga em 4 bovinos e a dilatação da ampola retal em 2 . Dois cavalos apresentaram lesões da pele causadas por traumatismos. As lesões histológicas foram de encefalomielite e meningite difusa não supurativa. Nos equiinos e em um caprino com evolução clínica de 35 dias as lesões foram mais severas, observando-se necrose neuronal, neuronofagia e presença de esferóides axonais. Corpúsculos de Negri foram observados em $87 \%$ (20/23) dos bovinos examinados e em 83\% (5/6) dos ovinos e caprinos. Nessas 3 espécies os corpúsculos foram mais freqüentes no cerebelo, mas ocorreram também no tronco encefálico, medula e cérebro. Em cavalos, corpúsculos de Negri foram menos numerosos, sendo observados somente no córtex de um animal e no córtex e hipocampo em outro. No gânglio trigeminal, as lesões histológicas e os corpúsculos de Negri foram menos freqüentes que no SNC. Esses resultados mostram que na raiva dos herbívoros os sinais clínicos e a distribuição das lesões histológicas do SNC são variáveis, e que para o correto diagnóstico da enfermidade são necessários um bom exame clínico e o estudo histológico das diferentes regiões do SNC. Sugere-se, também, que perante resultados negativos nos testes de imunofluorescência e inoculação em camundongos, estes devam ser repetidos com amostras de diferentes regiões do SNC. Utilizando-se dados sobre a frequiência de doenças, de 4 laboratórios de diagnóstico, foi realizada uma estimativa das mortes de bovinos causadas pela raiva, anualmente, em 3 Estados. Na Paraíba, com uma população de 918.262 bovinos, o número de mortes é estimado em 8.609 cabeças por ano. No Mato Grosso do Sul, com uma população de 23 milhões de bovinos, as perdas por raiva são estimadas em 149.500 cabeças e, no Rio Grande do Sul, com uma população de 13 milhões de bovinos, as mortes são estima- das em 13.000 a 16.250 animais por ano. Se estas estimativas forem extrapoladas para todo o Brasil, com 195 milhões de bovinos, as mortes podem ser estimadas em 842.688 cabeças por ano.

TERMOS DE INDEXAÇÃO: Raiva, bovinos, ovinos, caprinos, eqüinos, patologia, sinais clínico, importância econômica.

\section{INTRODUÇÃO}

A raiva, causada por um vírus RNA, do gênero Lyssavirus, da família Rhabdoviridae, é uma das viroses mais importantes para a pecuária e para a saúde pública no Brasil. Está distribuída em quase todo o mundo, tanto nos animais domésticos, quanto em animais silvestres, que servem como reservatórios por longos períodos (Acha \& Szyfres 1986). Heinemann et al. (2002) identificaram duas variantes de vírus rábico no Brasil, uma do ciclo silvestre, isolada de morcegos e bovinos e outra do ciclo urbano, isolada de cães, não havendo diferenças entre os isolamentos de bovinos e os de Desmodus rotundus. Por outro lado, Germano et al. (1990) em um trabalho com 13 amostras de vírus rábico, isoladas de diferentes espécies e oriundas de diversas regiões do Brasil, identificaram cinco variantes do vírus da raiva e possíveis fracassos de vacinação foram associados às variações antigênicas. Recentemente, no semi-árido da Paraíba, foi confirmada a existência de cinco variantes do vírus da raiva: canina, raposa 1 , raposa 2 , morcegos insetívoros e morcegos hematófagos, distintas geneticamente de amostras do Brasil e do mundo estudadas anteriormente (Gomes 2004). Até o momento as variantes de vírus isoladas de raposa e morcegos insetívoros não têm sido encontradas em herbívoros domésticos no Brasil.

No Brasil, a raiva é, na maioria das vezes, transmitida pelo morcego hematófago Desmodus rotundus; no entanto, outros morcegos hematófagos (Diphylla ecaudata e Diaemus youngii) assim como cães podem transmitir a doença (Fernandes 2001). Na região Nordeste o vírus é freqüientemente isolado de raposas (Dusicyon vetulus), sendo provável que este carnívoro esteja envolvido na transmissão da doença para os herbívoros (Barros et al. 1989, Araúijo 2002, Gomes 2004). Nos países da América Latina e do Caribe onde são encontrados os morcegos hematófagos, por muito tempo se pensou que estes fossem os únicos responsáveis pelos casos de raiva dos herbívoros. No entanto, o vírus da raiva já foi isolado de outros animais silvestres terrestres, como o lobo-guará, coiote, mangusto, quati, cangambá, guaxinim e raposas (Hayashi et al. 1984, Barros 1989, Organização Pan-Americana de Saúde 2001, Rede Interagencial de Informação para a Saúde 2002), contudo, poucos são os trabalhos relacionando estas espécies como transmissores do vírus para os herbívoros (Bacon 1985). No Ceará, existem relatos de isolamento do vírus da raiva de sagüis, Calithrix jacchus (Morais et al. 2000).

Na América Latina, na qual a população de bovinos expostos sob risco é de aproximadamente 70 milhões (King \& Turner 
1993), estima-se uma mortalidade anual que varia de 100.000 a 500.000 bovinos (Swanepoel 1994), com um prejuízo de 50 milhões de dólares americanos para a indústria pecuária (King \& Turner 1993). No Brasil, estima-se que a raiva seja responsável pela morte de 30.000 (Rodrigues da Silva et al. 2000) a 40.000 (Heinemann et al. 2002) bovinos anualmente, causando perdas anuais estimadas em 15 milhões de dólares (Heinemann et al. 2002). No Rio Grande do Sul, no Laboratório Regional de Diagnóstico da Universidade Federal de Pelotas, a raiva representou 2,06\% dos casos de bovinos recebidos entre 1978 e 1998, 2\% dos casos de eqüinos e $0,7 \%$ dos casos de ovinos (Riet-Correa et al. 1999). Nesse mesmo Estado, na Universidade Federal de Santa Maria, a raiva representou 2,5\% de um total de 6.021 casos em bovinos (Sanches et al. 2000). No Mato Grosso do Sul, entre os anos de 2000 e 2004 a raiva representou $13 \%$ de todos os casos diagnosticados em bovinos (Lemos 2005).

No Brasil, a raiva tem sido pouco estudada em equiinos. Em São Paulo entre os anos de 1980 e 1994 foram diagnosticados 983 casos de raiva em bovinos e 111 em equiinos (Peixoto et al. 2000), enquanto que no Rio Grande do Sul de 1978-1998 foram diagnosticados 12 casos em equïnos e 77 em bovinos (Riet-Correa et al. 1999).

A raiva é uma doença rara em caprinos e ovinos, mas estes são altamente susceptíveis à infecção quando expostos experimentalmente ao vírus (Gomes 2004). No Brasil têm sido raros os diagnósticos de raiva em ovinos e não há publicação de diagnósticos em caprinos. ${ }^{7}$ No Rio Grande do Sul, nos anos de 19781982 foram diagnosticados 4 surtos de raiva em ovinos, sendo que em dois deles a doença foi transmitida por cães (Riet-Correa et al. 1983). Mais recentemente, no mesmo Estado foi diagnosticada raiva em ovinos transmitida por morcegos hematófagos em duas fazendas (Barros 2003).

Em bovinos, a doença apresenta-se tanto na forma paralítica, como na furiosa, sendo a primeira, a mais freqüente (Summers et al. 1995, Langohr et al. 2003). Portanto, os sinais clínicos mais freqüentes são incoordenação dos membros pélvicos, seguida de paresia e paralisia flácida, decúbito lateral e sialorréia (Rondon et al. 1995, Langohr et al. 2003). Sinais clínicos da forma furiosa, como agressividade e mugidos freqüentes, são discretos, assim como prurido intenso com irritação cutânea (Langohr et al. 2003).

Em ovinos, na raiva transmitida por cães a doença caracterizou-se por alterações do comportamento, agressões a outros animais e ao homem, batidas da cabeça contra cercas e objetos e convulsões (Riet-Correa et al. 1983); enquanto que na doença transmitida por morcegos hematófagos os sinais foram de dificuldade de locomoção dos membros posteriores, tremores musculares, convulsões, opistótono e decúbito lateral (Cláudio Barros, 2003. Universidade Federal de Santa Maria. Comunicação pessoal). 0 curso clínico dos ovinos foi de 3-5 dias nos casos transmitidos por morcegos e 7-10 dias nos casos transmitidos por cães.

Em eqüinos, a manifestação clínica é muito variável, incluindo tanto a forma paralítica, quanto a forma furiosa da doença. Esta última foi observada em $43 \%$ de um grupo de 21 eqüinos

\footnotetext{
${ }^{7}$ Um Surto de raiva em caprinos descrito neste trabalho foi apresentado no XXIX Congresso Brasileiro de Medicina Veterinária, em Gramado, RS, por Lima et al. (2002).
}

infectados experimentalmente, nos quais o período médio de incubação foi de 12 dias e a duração média da doença de 5,5 dias (Hudson et al. 1996).

As lesões de raiva são geralmente limitadas ao sistema nervoso central (Jones et al. 2000). Os achados histológicos são variáveis, distribuindo-se principalmente no tronco encefálico, cerebelo e medula espinhal (Langohr et al. 2003), hipocampo e gânglios trigeminais (Jones et al. 2000), podendo, inclusive ser discretas ou ausentes (Jubb \& Huxtable 1993). As lesões são caracterizadas por acúmulos perivasculares com infiltrado celular, principalmente de linfócitos, e em menor grau, macrófagos e plasmócitos (Carlton \& McGavin 1998, Langohr et al. 2003), microgliose, às vezes acentuada, graus variáveis de degeneração neuronal e ganglioneurite (Carlton \& McGavin 1998) e necrose neuronal (Langohr et al. 2003). Inclusões acidofílicas intracitoplasmáticas, denominadas corpúsculos de Negri, características da doença (Swanepoel 1994, Jones et al. 2000), podem ser encontradas em diferentes áreas do sistema nervoso central, embora sejam mais freqüientes nas células de Purkinje do cerebelo dos bovinos (Swanepoel 1994, Jones et al. 2000, Langohr et al. 2003). A freqüência do aparecimento dos corpúsculos de Negri é inversamente proporcional ao grau de inflamação e não estão presentes em até $30 \%$ dos casos de raiva, pois certas cepas do vírus não produzem corpúsculos de inclusão (Braund et al. 1987, Jubb \& Huxtable 1993). Em eqüinos os corpúsculos de inclusão são menos freqüientes do que em bovinos (Peixoto et al. 2000).

O apoio laboratorial é imprescindível para o diagnóstico da raiva, sendo que, atualmente, a imunofluorescência direta em tecidos refrigerados ou congelados é a técnica de preferência para diagnóstico da raiva pela sua rapidez e acurácia (Zimmer et al. 1990). Porém, a inoculação intracerebral em camundongos é mais segura, mas tem a desvantagem de ser demorada (Germano et al. 1977). No entanto, resultados discrepantes entre as duas provas são freqüentes (Peixoto et al 2000, Gomes 2004, Lemos 2005) e, dependendo da localização das lesões e das amostras analisadas, ambos diagnósticos podem ser negativos em casos de raiva; Silva et al. (1974) obtiveram resultados positivos no bulbo de um eqüino e na medula de outro, enquanto que amostras de corno de Ammon, córtex e cerebelo foram negativas para as duas provas. Esses fatos chamam a atenção sobre a importância de conhecer a localização das lesões no sistema nervoso da espécie afetada, para realizar as provas de diagnóstico com mais chances de serem positivas. Além disso, evidenciam a importância do exame histológico sistemático em diferentes regiões do encéfalo para o diagnóstico da enfermidade, que é extremamente importante, também, para o diagnóstico diferencial com outras doenças do sistema nervosos dos herbívoros. Por outro lado, a localização da lesão das diferentes doenças no sistema nervoso pode ser estabelecida mediante um exame clínico correto determinando os sinais clínicos e a provável localização das lesões responsáveis por esses sinais.

O objetivo deste estudo foi o de descrever os aspectos clínicos e histopatológicos de bovinos, eqüinos, ovinos e caprinos acometidos pela raiva, determinando a distribuição das lesões histológicas no sistema nervoso, visando subsidiar o diagnóstico histológico, imunofluorescência direta e inoculação em camundongos. 


\section{MATERIAL E MÉTODOS}

Foram estudados 24 surtos de raiva em bovinos ( 25 casos), 4 em eqüinos (5 casos), 2 em caprinos ( 2 casos) e 2 em ovinos ( 4 casos), diagnosticados no Hospital Veterinário (HV) da Universidade Federal de Campina Grande (UFCG), Campus de Patos, Paraíba, de janeiro de 2002 a agosto de 2004. No total foram estudados 25 casos de bovinos (2 de um mesmo surto), 5 de eqüinos ( 2 de um mesmo surto), 4 de ovinos ( 3 de um mesmo surto), e 2 de caprinos. Quatorze bovinos, 3 eqüinos, 2 ovinos e um caprino chegaram vivos ao $\mathrm{HV}$ ou foram avaliados clinicamente em visitas à fazendas; posteriormente foram sacrificados e necropsiados. O exame clínico foi realizado seguindo a metodologia descrita por Riet-Correa et al. (2002). Dois equiinos, 1 ovino e 2 bovinos chegaram ao HV já mortos. Em 1 caprino, 1 ovino e 9 bovinos o sistema nervoso central foi enviado por Médicos Veterinários autônomos ou pela Secretaria da Agricultura do Estado da Paraíba. Nos casos que chegaram mortos ao HV ou nos casos que somente o sistema nervoso foi enviado, os sinais clínicos e os dados epidemiológicos foram informados pelos veterinários e/ou pelos proprietários.

Durante a necropsia foram coletados órgãos da cavidade torácica, cavidade abdominal, gânglios linfáticos, sistema nervoso central (SNC) e gânglio trigeminal. O SNC incluiu todo o encéfalo e a medula espinhal. Amostras dos diferentes órgãos, metade do encéfalo, diferentes porções da medula espinhal (cervical, dorsal e lombar) e gânglio trigeminal foram fixados em formol tamponado a $10 \%$ para estudo histológico. Já outra metade do encéfalo e a medula espinhal foram refrigeradas e enviadas ao Laboratório de Virologia da UFCG, Campus de Patos, para exame de imunofluorescência direta e inoculação em camundongos. A técnica de imunofluorescência foi realizada pelo método descrito por Goldwasser \& Kissling (1958), com modificação descrita por Dean et al. (1996). A inoculação em camundongos foi realizada segundo a técnica de Koprowski (1996).

Em 21 casos de bovinos, 5 eqüinos, 2 caprinos e 1 ovino o diagnóstico foi realizado pelas técnicas de imunofluorescência e/ou inoculação em camundongos. Em 4 casos de bovinos (Casos 20, 22, 23 e 24) e 3 de ovinos (Casos 2, 3 e 4, de um mesmo surto) que não foram examinados por imunofluorescência ou inoculação de camundongos, o diagnóstico foi realizado pelas lesões histológicas características e a presença de corpúsculos de Negri.

Uma vez fixado, o material foi embebido em parafina, cortado em seções de 5ìm e corado com hematoxilina-eosina. O sistema nervoso central foi cortado transversalmente em fatias de $3-5 \mathrm{~mm}$ de espessura, contemplando as seguintes regiões para estudo histológico: córtex (frontal, parietal, temporal e occipital), núcleos de base, tálamo, hipocampo, tubérculos quadrigêmeos, ponte, cerebelo, bulbo e medula espinhal (cervical, dorsal e lombar). Em cada um desses fragmentos coletados foram avaliadas as seguintes lesões: acúmulo perivascular de células linfocitárias, leptomeningite, gliose focal, multifocal ou difusa e corpúsculos de Negri, classificando-as como, discretas $(+)$, moderadas $(++)$ e acentuadas $(+++)$.

Em 2 casos em bovinos (Casos 9 e 19) não foi realizado exame histológico e, em 2 casos (Casos 20 e 24) foi feito exame histopatológico apenas do tronco encefálico e cerebelo. $O$ estudo da medula cervical foi feito em 17 casos de bovinos, e, nas porções dorsal e lombar em 12 casos. $O$ gânglio trigeminal foi estudado em 13 casos.

\section{RESULTADOS}

Durante o período de janeiro de 2002 a agosto de 2004 foram diagnosticados 24 surtos ( 25 casos) de raiva em bovinos, 4 surtos (5 casos) em eqüinos, 2 surtos ( 4 casos) em ovinos e 2 surtos ( 2 casos) em caprinos. A frequiência da raiva, em cada espécie, em relação às outras doenças e às doenças do sistema nervoso são apresentadas no Quadro 1. O mês de ocorrência de cada surto, nas diferentes espécies, apresenta-se na Fig.1. Em todos

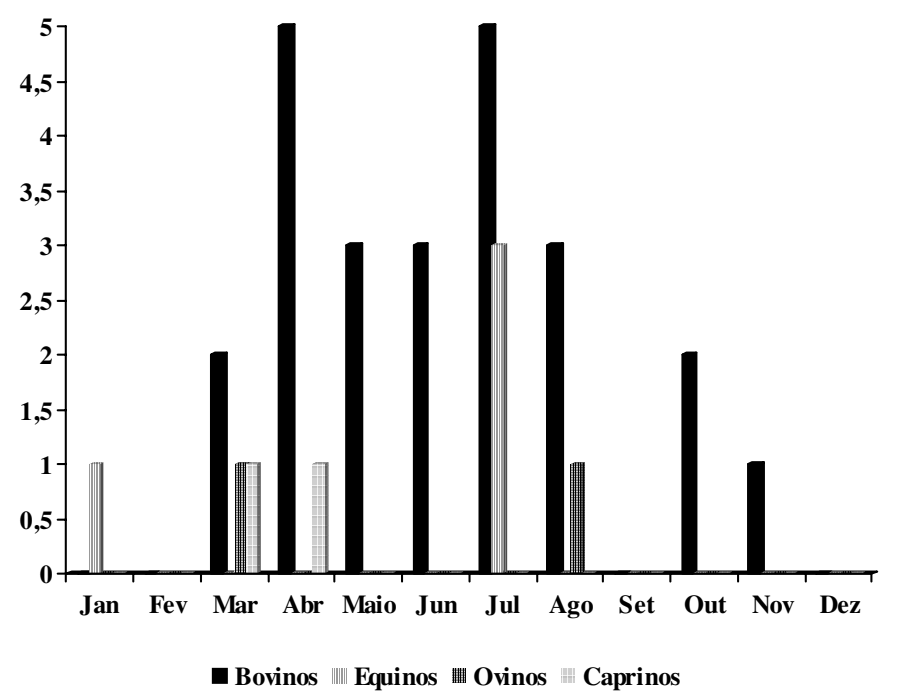

Fig.1. Época de ocorrência dos surtos de raiva em bovinos, eqüinos, ovinos e caprinos.

Quadro 1. Freqüência dos surtos de raiva em bovinos, caprinos, ovinos e eqüinos diagnosticados no HV da UFCG, no período de janeiro de 2002 a agosto de 2004

\begin{tabular}{cccccccc}
\hline Espécie & $\begin{array}{c}\text { No de ma- } \\
\text { teriais }\end{array}$ & \multicolumn{2}{c}{$\begin{array}{c}\text { Doenças do SNC } \\
\text { № }\end{array}$} & $\%$ & No & $\begin{array}{c}\text { Raiva em relação às } \\
\text { \%oenças do SNC }\end{array}$ & $\begin{array}{c}\text { População na } \\
\text { diagnósticos }\end{array}$ \\
\hline Bovina & 128 & 38 & 29,68 & 24 & 63,16 & 18,75 & 918.262 \\
Caprina & 149 & 17 & 11,41 & 2 & 11,76 & 1,34 & 608.155 \\
Ovina & 129 & 14 & 10,85 & 2 & 14,28 & 1,55 & 376.983 \\
Eqüina & 43 & 17 & 39,53 & 4 & 23,53 & 9,30 & 51.698 \\
Total & 449 & 90 & 20,04 & 32 & 35,55 & 7,13 &
\end{tabular}

a Materiais da Região Nordeste, enviados por veterinários da área de influência do HV ou necropsias realizadas no $\mathrm{HV}$ ou em fazendas. Cada material corresponde à ocorrência de uma doença em uma fazenda, independente de que em um mesmo surto fossem necropsiados ou enviadas amostras de mais de um animal. Não foram incluídos materiais de outras regiões do País ou materiais para vigilância de BSE.

b Dados do IBGE (2001). 


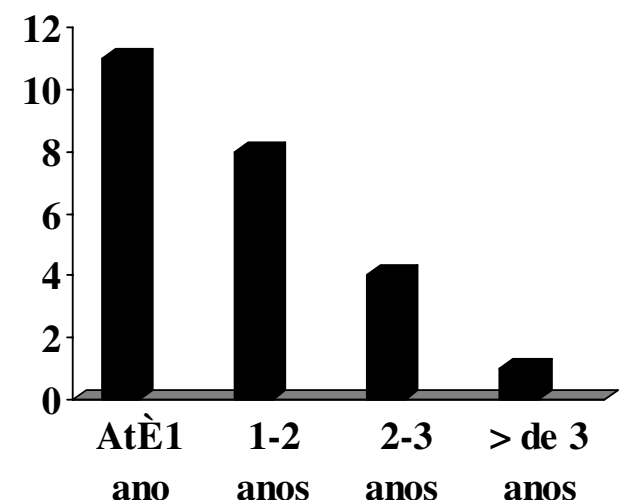

Fig.2. Distribuição dos 24 surtos de raiva em bovinos segundo a idade.

os surtos os animais deixaram de morrer após a vacinação dos rebanhos, mas em um surto em bovinos ainda morreram 3 animais em um período de 5 dias após a vacinação.

\section{Raiva em bovinos}

Todos os surtos em bovinos ocorreram na Paraíba, 22 no Sertão, 1 no Cariri e 1 no Agreste. A distribuição por municípios foi a seguinte: Santa Luzia, 5 surtos; Patos, 5; Pombal, 2; São José do Sabugí, 2; São Mamede, 2; Boa Vista, Cacimba de Areia, Curral Velho, Lagoa Seca, Várzea, Santa Terezinha, Itaporanga e São José do Bomfim, 1 surto em cada. Não houve predileção por sexo ou raça, apesar das fêmeas terem sido mais acometidas do que os machos. Animais sem raça definida foram os mais acometidos, devido a maior predominância desses na região. A idade dos animais variou dos 3 meses a 3 anos e meio, com predominância para animais com até 1 ano de idade (Fig.2).

A doença atingiu rebanhos com número variável de bovinos, desde pequenos rebanhos com 3 animais a grandes rebanhos com 1.200 animais. A morbidade variou de $0,08 \%$ a 33,3\% (média de $7,5 \%$ ) e a letalidade foi de $100 \%$. Todos os surtos, exceto um, aconteceram em animais não vacinados. $O$ surto que aconteceu em animais vacinados afetou um único bovino jovem, que não tinha sido revacinado após a primovacinação. Em todos os surtos a doença foi controlada após a vacinação, sendo que em um surto ainda morreram 3 bovinos após a mesma.

A evolução clínica da doença variou de 2-8 dias, com média de 4,7 dias. Os sinais clínicos, observados nos bovinos com diagnóstico de raiva, estão representados em valores absolutos e em percentuais no Quadro 2. A intensidade dos sinais clínicos em relação às diferentes regiões do SNC são vistos no Quadro 3.

Na necropsia, foram observadas distensão da bexiga em 4 animais e a ampola retal distendida e repleta de fezes em 2 animais. Outros achados sem significação para o diagnóstico, como enfisema pulmonar, congestão, hidrotórax, hidropericárdio e fígado de coloração amarelada com a vesícula biliar distendida, foram observados em alguns animais.

Os achados histopatológicos foram caracterizados por acúmulos perivasculares de células mononucleares, gliose focal, multifocal ou difusa, meningite e corpúsculos de inclusão intracitoplasmáticos. A distribuição e intensidade das lesões inflamatórias dos casos de raiva em bovinos são observadas no Quadro 4. As lesões do cérebro e cerebelo afetavam principal-
Quadro 2. Freqüência dos diferentes sinais clínicos observados em 25 casos de raiva em bovinos diagnosticados no período de janeiro de 2002 a agosto de 2004 na Paraíba

\begin{tabular}{|c|c|c|}
\hline Sinais clínicos & № & $\%$ \\
\hline \multicolumn{3}{|l|}{ Cérebro } \\
\hline Agressividade & 3 & 12 \\
\hline Alheio ao ambiente & 1 & 4 \\
\hline Anorexia & 4 & 16 \\
\hline Apatia & 5 & 20 \\
\hline Bruxismo (ranger de dentes) & 4 & 16 \\
\hline Cegueira & 4 & 16 \\
\hline Fotofobia & 2 & 8 \\
\hline Movimentos involuntários & 1 & 4 \\
\hline Movimentos de pedalagem & 2 & 8 \\
\hline Mudanças de atitude & 1 & 4 \\
\hline Tiques nervosos & 1 & 4 \\
\hline \multicolumn{3}{|l|}{ Tronco encefálico } \\
\hline Ataxia & 5 & 20 \\
\hline Ausência de reflexo pupilar & 1 & 4 \\
\hline Dificuldade de deglutição & 5 & 20 \\
\hline Diminuição da sensibilidade facial & 1 & 4 \\
\hline Estrabismo & 4 & 16 \\
\hline Exoftalmia & 1 & 4 \\
\hline Flacidez da língua & 3 & 12 \\
\hline Nistagmo & 1 & 4 \\
\hline Paralisia do maxilar & 2 & 8 \\
\hline Protusão da membrana nictante & 1 & 4 \\
\hline Pupilas dilatadas (midríase) & 2 & 8 \\
\hline Salivação & 12 & 48 \\
\hline Trismo mandibular & 1 & 4 \\
\hline \multicolumn{3}{|l|}{ Cerebelo } \\
\hline Opistótono & 3 & 12 \\
\hline Tremores da cabeça (de intenção) & 4 & 16 \\
\hline Tremores musculares & 3 & 12 \\
\hline \multicolumn{3}{|l|}{ Medula espinhal } \\
\hline Ausência de reflexo anal & 4 & 16 \\
\hline Ausência do reflexo de flexão & 1 & 4 \\
\hline Claudicação & 2 & 8 \\
\hline Decúbito esternal & 10 & 40 \\
\hline Decúbito lateral & 15 & 60 \\
\hline Diminuição do reflexo do panículo lombo-sacro & 1 & 4 \\
\hline Flacidez da cauda & 2 & 8 \\
\hline Hiperestesia & 1 & 4 \\
\hline Hiperreflexia & 1 & 4 \\
\hline Incoordenação & 18 & 72 \\
\hline Paralisia da cauda & 2 & 8 \\
\hline Paralisia dos membros torácicos & 5 & 20 \\
\hline Paralisia dos membros pélvicos & 12 & 48 \\
\hline Paresia de membros pélvicos & 6 & 24 \\
\hline Paresia de membros torácicos & 1 & 4 \\
\hline Prolapso retal & 1 & 4 \\
\hline Tenesmo & 2 & 8 \\
\hline
\end{tabular}

mente a substância cinzenta e no tronco encefálico eram mais freqüientes nos diferentes núcleos do que na substância branca. As lesões da medula eram observadas, principalmente, no corno ventral da substância cinzenta. As lesões do gânglio trigeminal foram caracterizadas por ganglioneurite, com infiltrado inflamatório de linfócitos nos espaços interneuronais. A presença de corpúsculos intracitoplamáticos de inclusão (corpúsculos de Negri) nos casos de raiva em bovinos foi de $87 \%$ (20 animais de um total de 23 estudados). A distribuição destes corpúsculos no sistema nervoso é vista no Quadro 5. Os corpúsculos foram observados com maior frequiência e intensidade nos animais 
Quadro 3. Intensidade dos sinais clínicos de 25 casos de raiva em bovinos referentes a diferentes regiões do SNC diagnosticados no período de janeiro de 2002 a agosto de 2004 na Paraíba

\begin{tabular}{|c|c|c|c|c|}
\hline Caso $\mathrm{n}^{\mathrm{o}}$ & Cérebro & Tronco encefálico & Cerebelo & Medula espinhal \\
\hline 1 & - & $+^{a}$ & + & +++ \\
\hline 2 & - & + & - & +++ \\
\hline 3 & - & + & - & ++ \\
\hline 4 & ++ & +++ & ++ & +++ \\
\hline 5 & - & - & - & +++ \\
\hline 6 & - & +++ & + & +++ \\
\hline 7 & - & + & + & +++ \\
\hline 8 & - & + & + & +++ \\
\hline 9 & - & ++ & - & ++ \\
\hline 10 & +++ & +++ & + & + \\
\hline 11 & ++ & + & - & + \\
\hline $12^{b}$ & - & ++ & + & +++ \\
\hline 13 & - & ++ & + & +++ \\
\hline 14 & ++ & ++ & - & + \\
\hline 15 & - & ++ & + & +++ \\
\hline 16 & - & +++ & + & +++ \\
\hline 17 & - & + & - & +++ \\
\hline 18 & - & + & - & + \\
\hline 19 & ++ & ++ & - & + \\
\hline 20 & - & ++ & + & ++ \\
\hline 21 & ++ & + & - & ++ \\
\hline 22 & + & - & - & +++ \\
\hline 23 & +++ & +++ & - & + \\
\hline 24 & + & + & - & ++ \\
\hline 25 & + & + & + & ++ \\
\hline $\begin{array}{l}\text { Total de } \\
\text { positivos }\end{array}$ & 10 & 23 & 12 & 23 \\
\hline
\end{tabular}

a - Ausente, + discreta, ++ moderada, +++ acentuada; $^{b}$ Os Casos 12 e 13 pertencem a um mesmo surto. que sobreviveram por mais de 4 dias. O tamanho e número dos corpúsculos no pericário dos neurônios foram variáveis, sendo que, quanto mais corpúsculos numa célula, menor o seu tamanho. Em alguns casos os corpúsculos de Negri foram mais freqüentes em áreas com reação inflamatória discreta, ou mesmo sem reação inflamatória, do que em áreas com lesões inflamatórias severas.

A freqüiência e intensidade das lesões nas diferentes regiões do sistema nervoso, em relação à freqüência e intensidade dos sinais clínicos característicos dessas localizações apresentam-se no Quadro 6.

\section{Raiva em eqüinos}

Em eqüinos não houve predileção por sexo e raça. A idade variou desde os 4 meses até 20 anos. Três surtos ocorreram no sertão da Paraíba, os Surtos 1 (Caso 1) e 2 (Casos 2 e 3) no município de São José do Bonfim e um surto (Caso 4) no município de Patos. Outro surto (Caso 5) foi diagnosticado no município de Taipú na zona da mata do Rio Grande do Norte. Nos Surtos 1 e 3 morreu somente um eqüino em cada surto. No Surto 2 morreram 2 eqüinos e 5 bovinos. Nos Surto 4 morreram 3 de 10 equiinos. $O$ eqüino 3 havia sido vacinado 5 a 6 meses antes de apresentar a doença. Nos Surtos 1 e 3 os animais estavam estabulados e alimentados com ração volumosa e concentrados. Os demais animais estavam a campo.

A evolução clínica da raiva em eqüinos foi de 2 dias no eqüino 2 e de 8 dias nos Eqüinos 1, 4 e 5. No Eqüino 3 não foi informado o curso clínico. Os sinais clínicos e a sua frequiência em relação

Quadro 4. Distribuição e intensidade das lesões inflamatórias em 23 casos de raiva em bovinos diagnosticados no período de janeiro de 2002 a agosto de 2004 na Paraíba

\begin{tabular}{|c|c|c|c|c|c|c|c|c|c|c|c|c|c|c|c|}
\hline Caso $n^{\circ}$ & $\mathrm{CF}^{\mathrm{a}}$ & $\mathrm{CP}$ & CT & $\mathrm{CO}$ & NB & $\mathrm{TL}$ & $\mathrm{HC}$ & TQ & PT & $\mathrm{CE}$ & $\mathrm{BL}$ & $\mathrm{MC}$ & MD & ML & GT \\
\hline 1 & - & + & - & - & - & + & - & +++ & +++ & +++ & +++ & +++ & +++ & ++ & - \\
\hline 2 & - & - & - & - & - & - & - & + & ++ & - & + & + & + & + & $\mathrm{Na}^{*}$ \\
\hline 3 & + & - & - & + & + & - & - & +++ & +++ & +++ & ++ & +++ & +++ & +++ & ++ \\
\hline 4 & +++ & +++ & +++ & +++ & +++ & +++ & ++ & +++ & +++ & + & +++ & +++ & $\mathrm{Na}$ & $\mathrm{Na}$ & $\mathrm{Na}$ \\
\hline 5 & - & - & - & - & - & - & - & - & - & - & - & - & + & +++ & + \\
\hline 6 & - & - & + & + & ++ & + & - & +++ & +++ & ++ & +++ & +++ & +++ & + & +++ \\
\hline 7 & + & + & + & - & + & + & + & $\mathrm{Na}$ & + & ++ & ++ & +++ & $\mathrm{Na}$ & $\mathrm{Na}$ & $\mathrm{Na}$ \\
\hline 8 & + & - & + & - & + & + & - & ++ & - & - & $\mathrm{Na}$ & $\mathrm{Na}$ & $\mathrm{Na}$ & $\mathrm{Na}$ & $\mathrm{Na}$ \\
\hline 10 & +++ & +++ & ++ & ++ & +++ & ++ & +++ & +++ & +++ & +++ & +++ & $\mathrm{Na}$ & $\mathrm{Na}$ & $\mathrm{Na}$ & $\mathrm{Na}$ \\
\hline 11 & + & + & + & - & + & + & + & + & ++ & - & $\mathrm{Na}$ & + & $\mathrm{Na}$ & $\mathrm{Na}$ & $\mathrm{Na}$ \\
\hline $12^{b}$ & - & - & - & - & - & - & - & + & + & ++ & ++ & + & + & ++ & + \\
\hline 13 & - & - & - & - & - & - & - & + & + & ++ & - & + & + & + & - \\
\hline 14 & ++ & ++ & ++ & + & ++ & ++ & + & +++ & +++ & ++ & +++ & + & $\mathrm{Na}$ & $\mathrm{Na}$ & +++ \\
\hline 15 & + & - & + & - & + & + & - & ++ & ++ & + & ++ & + & - & - & + \\
\hline 16 & - & + & - & - & + & + & - & ++ & ++ & + & ++ & + & + & + & - \\
\hline 17 & + & - & + & - & +++ & + & + & +++ & ++ & + & +++ & ++ & $\mathrm{Na}$ & $\mathrm{Na}$ & + \\
\hline 19 & - & + & + & - & + & + & - & ++ & + & + & + & + & $\mathrm{Na}$ & $\mathrm{Na}$ & $\mathrm{Na}$ \\
\hline 20 & - & - & + & - & + & + & - & ++ & + & + & ++ & + & ++ & +++ & + \\
\hline 21 & $\mathrm{Na}$ & $\mathrm{Na}$ & $\mathrm{Na}$ & $\mathrm{Na}$ & $\mathrm{Na}$ & $\mathrm{Na}$ & $\mathrm{Na}$ & ++ & ++ & ++ & ++ & $\mathrm{Na}$ & $\mathrm{Na}$ & $\mathrm{Na}$ & $\mathrm{Na}$ \\
\hline 22 & + & - & - & - & - & - & - & + & + & - & + & + & +++ & +++ & ++ \\
\hline 23 & + & - & ++ & + & + & + & + & + & + & - & + & - & - & - & + \\
\hline 24 & - & - & + & - & + & $\mathrm{Na}$ & - & + & - & + & - & - & - & + & + \\
\hline 25 & $\mathrm{Na}$ & - & $\mathrm{Na}$ & $\mathrm{Na}$ & $\mathrm{Na}$ & $\mathrm{Na}$ & + & + & $\mathrm{Na}$ & ++ & ++ & $\mathrm{Na}$ & $\mathrm{Na}$ & $\mathrm{Na}$ & $\mathrm{Na}$ \\
\hline Total de & $11 / 21$ & $8 / 22$ & $13 / 21$ & $6 / 21$ & $15 / 21$ & $6 / 20$ & $8 / 22$ & $21 / 22$ & $19 / 22$ & $6 / 23$ & $18 / 21$ & $16 / 19$ & $10 / 13$ & $11 / 13$ & \\
\hline
\end{tabular}

positivos/estudados

${ }^{a} \mathrm{CF}=$ córtex frontal, $\mathrm{CP}=$ córtex parietal, $\mathrm{CF}=$ córtex frontal, $\mathrm{CP}=$ córtex parietal, $\mathrm{CT}=$ córtex temporal, $\mathrm{CO}=$ córtex occipital, $\mathrm{NB}=$ núcleos de base, $\mathrm{TL}=$ tálamo, $\mathrm{HC}=$ hipocampo, $\mathrm{TQ}=$ tubérculos quadrigêmeos, $\mathrm{PT}=$ ponte, $\mathrm{CE}=$ cerebelo, $\mathrm{BL}=\mathrm{Bulbo}, \mathrm{MC}=$ medula cervical, $\mathrm{MD}=$ medula dorsal, $\mathrm{ML}=\mathrm{medula}$ lombar, GT= gânglio trigeminal; ${ }^{b}$ Os Casos 12 e 13 pertencem a um mesmo surto; ${ }^{c}$ - Ausente, + discreta, ++ moderada, +++ acentuada; ${ }^{d}$ Na $=$ Não avaliado. 
Quadro 5. Presença de corpúsculos de inclusão em 23 casos de raiva em bovinos diagnosticados no período de janeiro de 2002 a agosto de 2004 na Paraíba

\begin{tabular}{|c|c|c|c|c|c|c|c|c|c|c|c|c|c|c|c|c|}
\hline Caso $n^{\circ}$ & $\mathrm{CF}^{\mathrm{a}}$ & $\mathrm{CP}$ & CT & $\mathrm{CO}$ & NB & $\mathrm{TL}$ & $\mathrm{HC}$ & TQ & PT & CE & $\mathrm{BL}$ & MC & MD & ML & GT & $+1-$ \\
\hline 1 & - & - & - & - & - & - & - & - & - & - & - & - & - & - & - & - \\
\hline 2 & - & - & - & - & - & - & $++^{c}$ & + & + & ++ & + & + & + & - & $\mathrm{Na}^{\mathrm{d}}$ & + \\
\hline 3 & - & - & - & - & - & - & - & - & - & - & - & - & - & - & - & - \\
\hline 4 & +++ & +++ & +++ & ++ & + & +++ & +++ & +++ & + & +++ & +++ & +++ & $\mathrm{Na}$ & $\mathrm{Na}$ & $\mathrm{Na}$ & + \\
\hline 5 & - & ++ & - & - & - & - & - & - & - & + & + & + & - & + & - & + \\
\hline 6 & - & - & - & - & - & - & - & - & - & - & - & + & + & - & - & + \\
\hline 7 & - & - & - & - & - & - & - & $\mathrm{Na}$ & + & ++ & - & - & $\mathrm{Na}$ & $\mathrm{Na}$ & $\mathrm{Na}$ & + \\
\hline 8 & + & ++ & ++ & + & + & + & +++ & + & - & +++ & $\mathrm{Na}$ & $\mathrm{Na}$ & $\mathrm{Na}$ & $\mathrm{Na}$ & $\mathrm{Na}$ & + \\
\hline 10 & +++ & +++ & ++ & +++ & +++ & ++ & +++ & ++ & + & +++ & + & $\mathrm{Na}$ & $\mathrm{Na}$ & $\mathrm{Na}$ & $\mathrm{Na}$ & + \\
\hline 11 & +++ & ++ & +++ & + & ++ & + & +++ & + & + & +++ & $\mathrm{Na}$ & ++ & $\mathrm{Na}$ & $\mathrm{Na}$ & $\mathrm{Na}$ & + \\
\hline $12^{b}$ & + & + & - & - & + & - & - & + & + & +++ & ++ & + & + & ++ & - & + \\
\hline 13 & + & + & - & - & - & - & + & + & + & +++ & + & + & + & +++ & - & + \\
\hline 14 & +++ & +++ & +++ & + & ++ & - & +++ & +++ & + & +++ & + & - & $\mathrm{Na}$ & $\mathrm{Na}$ & +++ & + \\
\hline 15 & - & - & - & - & + & - & - & - & + & ++ & + & + & - & - & - & + \\
\hline 16 & - & - & - & - & - & - & - & + & + & ++ & ++ & - & + & - & + & + \\
\hline 17 & + & - & - & - & + & - & - & + & + & - & - & - & $\mathrm{Na}$ & $\mathrm{Na}$ & - & + \\
\hline 19 & - & +++ & ++ & - & - & ++ & +++ & +++ & + & +++ & + & + & $\mathrm{Na}$ & $\mathrm{Na}$ & $\mathrm{Na}$ & + \\
\hline 20 & - & - & - & - & - & + & - & - & + & +++ & + & + & ++ & ++ & + & + \\
\hline 21 & $\mathrm{Na}$ & $\mathrm{Na}$ & $\mathrm{Na}$ & $\mathrm{Na}$ & $\mathrm{Na}$ & $\mathrm{Na}$ & $\mathrm{Na}$ & - & - & - & - & $\mathrm{Na}$ & $\mathrm{Na}$ & $\mathrm{Na}$ & $\mathrm{Na}$ & - \\
\hline 22 & - & - & - & - & - & - & - & - & + & ++ & ++ & - & + & ++ & - & + \\
\hline 23 & ++ & + & ++ & + & + & + & ++ & + & + & +++ & ++ & + & + & + & + & + \\
\hline 24 & +++ & + & +++ & + & +++ & $\mathrm{Na}$ & +++ & ++ & ++ & +++ & +++ & +++ & ++ & +++ & +++ & + \\
\hline 25 & $\mathrm{Na}$ & - & $\mathrm{Na}$ & $\mathrm{Na}$ & $\mathrm{Na}$ & $\mathrm{Na}$ & + & - & $\mathrm{Na}$ & - & - & $\mathrm{Na}$ & $\mathrm{Na}$ & $\mathrm{Na}$ & $\mathrm{Na}$ & + \\
\hline Total de & $10 / 21$ & $11 / 22$ & $8 / 21$ & $7 / 21$ & $10 / 21$ & $7 / 20$ & $11 / 22$ & $13 / 22$ & $16 / 22$ & $17 / 23$ & $14 / 21$ & $12 / 19$ & $9 / 13$ & $7 / 13$ & $5 / 14$ & $20 / 23$ \\
\hline
\end{tabular}

a $\mathrm{CF}=$ córtex frontal, $\mathrm{CP}=$ córtex parietal, $\mathrm{CF}=$ córtex frontal, $\mathrm{CP}=$ córtex parietal, $\mathrm{CT}=$ córtex temporal, $\mathrm{CO}=$ córtex occipital, $\mathrm{NB}=$ núcleos de base, $\mathrm{TL}=$ tálamo, $\mathrm{HC}=$ hipocampo, $\mathrm{TQ}=$ tubérculos quadrigêmeos, $\mathrm{PT}=$ ponte, $\mathrm{CE}=$ cerebelo, $\mathrm{BL}=\mathrm{Bulbo}, \mathrm{MC}=\mathrm{medula}$ cervical, $\mathrm{MD}=\mathrm{medula}$ dorsal, $\mathrm{ML}=\mathrm{medula}$ combar, GT= gânglio trigeminal; ${ }^{\mathrm{b}}$ Os Casos 12 e 13 pertencem a um mesmo surto; ${ }^{\mathrm{c}}-$ Ausente, + discreta, ++ moderada, +++ acentuada; ${ }^{\mathrm{d}} \mathrm{Na}=\mathrm{Não}$ avaliado.

Quadro 6. Sinais clínicos relacionados com a lesão na região do sistema nervoso central de 23 casos de raiva em bovinos diagnosticados no período de janeiro de 2002 a agosto de 2004 na Paraíba

\begin{tabular}{|c|c|c|c|c|c|c|c|c|}
\hline \multirow[t]{2}{*}{ Caso $\mathrm{n}^{\circ}$} & \multicolumn{2}{|l|}{ Cérebro } & \multicolumn{2}{|c|}{ Tronco encefálico } & \multicolumn{2}{|c|}{ Cerebelo } & \multicolumn{2}{|c|}{ Medula espinhal } \\
\hline & Sinais clínicos & Lesões & Sinais clínicos & Lesões & Sinais clínicos & Lesões & Sinais clínicos & Lesões \\
\hline 1 & - & $+^{a}$ & + & ++ & + & +++ & +++ & +++ \\
\hline 2 & - & - & + & ++ & - & + & +++ & + \\
\hline 3 & - & - & + & ++ & - & +++ & ++ & +++ \\
\hline 4 & ++ & +++ & +++ & +++ & ++ & +++ & +++ & +++ \\
\hline 5 & - & + & - & + & - & + & +++ & +++ \\
\hline 6 & - & + & +++ & +++ & + & ++ & +++ & +++ \\
\hline 7 & - & + & + & + & + & + & +++ & + \\
\hline 8 & - & + & + & + & + & ++ & +++ & $\mathrm{Na}$ \\
\hline 9 & - & $\mathrm{Na}^{\mathrm{C}}$ & ++ & $\mathrm{Na}$ & - & $\mathrm{Na}$ & ++ & $\mathrm{Na}$ \\
\hline 10 & +++ & +++ & +++ & +++ & + & +++ & + & $\mathrm{Na}$ \\
\hline 11 & ++ & + & + & + & - & ++ & + & + \\
\hline $12^{\mathrm{b}}$ & - & + & ++ & ++ & + & +++ & +++ & ++ \\
\hline 13 & - & + & ++ & + & + & ++ & +++ & +++ \\
\hline 14 & ++ & +++ & ++ & ++ & - & ++ & + & + \\
\hline 15 & - & + & ++ & ++ & + & ++ & +++ & + \\
\hline 16 & - & + & +++ & ++ & + & + & +++ & + \\
\hline 17 & - & + & + & +++ & - & + & +++ & + \\
\hline 18 & - & ++ & + & ++ & - & ++ & + & + \\
\hline 19 & ++ & $\mathrm{Na}$ & ++ & $\mathrm{Na}$ & - & $\mathrm{Na}$ & + & $\mathrm{Na}$ \\
\hline 20 & - & + & ++ & + & + & ++ & ++ & +++ \\
\hline 21 & ++ & $\mathrm{Na}$ & + & ++ & - & + & ++ & $\mathrm{Na}$ \\
\hline 22 & + & + & - & + & - & + & +++ & +++ \\
\hline 23 & +++ & ++ & +++ & + & - & +++ & + & + \\
\hline 24 & + & ++ & + & ++ & - & +++ & ++ & +++ \\
\hline 25 & + & + & + & + & + & ++ & ++ & $\mathrm{Na}$ \\
\hline Total & 10 & 20 & 25 & 23 & 12 & 23 & 25 & 19 \\
\hline
\end{tabular}

a Ausente, + discreta ++ moderada, +++ acentuada; ${ }^{b}$ Os Casos 12 e 13 pertencem a um mesmo surto; c $\mathrm{Na}=$ Não avaliado. 
Quadro 7. Sinais clínicos de raiva em eqüinos em casos diagnosticados no período de janeiro de 2002 a agosto de 2004 no HV da UFCG, Campus de Patos

\begin{tabular}{|c|c|c|c|c|c|}
\hline \multirow{2}{*}{$\begin{array}{l}\text { Sinais clínicos } \\
\text { Cérebro }\end{array}$} & \multicolumn{3}{|c|}{ Caso 1 Caso $2^{\mathrm{a}}$ Caso 3} & \multicolumn{2}{|c|}{ Caso 4 Caso } \\
\hline & & & & & \\
\hline Agressividade & - & - & - & $+b$ & - \\
\hline Andar em círculo & - & - & - & + & + \\
\hline Apatia & + & - & - & + & + \\
\hline Cegueira & - & - & - & + & - \\
\hline Mudanças de atitude & - & - & - & + & + \\
\hline Pressão da cabeça contra objetos & - & - & - & + & \\
\hline Ranger de dentes & - & - & - & + & - \\
\hline Sonolência & - & - & - & + & - \\
\hline Movimentos involuntários & - & - & - & + & - \\
\hline \multicolumn{6}{|l|}{ Tronco encefálico } \\
\hline Ataxia & + & - & - & + & + \\
\hline Ausência de reflexo pupilar & + & - & - & - & - \\
\hline Dificuldade de apreensão e mastigaçã & ão - & - & - & + & - \\
\hline Paresia lingual & - & - & - & + & - \\
\hline Ptose labial & - & - & - & + & - \\
\hline Retração do globo ocular & - & - & - & + & - \\
\hline \multicolumn{6}{|l|}{ Cerebelo } \\
\hline Perda de equilíbrio & - & - & - & - & + \\
\hline \multicolumn{6}{|l|}{ Medula espinhal } \\
\hline Decúbito esternal & - & - & - & + & - \\
\hline Decúbito lateral & - & + & + & - & - \\
\hline Incoordenação & + & + & - & + & + \\
\hline Paralisia dos membros pélvicos & - & + & + & - & - \\
\hline Paralisia dos membros torácicos & - & + & + & - & - \\
\hline Paresia de membros & + & + & + & + & - \\
\hline
\end{tabular}

a Os Casos 2 e 3 pertencem a um mesmo surto; ${ }^{\text {b }}$ - Ausente, + presente. à possível localização das lesões são apresentados no Quadro 7. Dos 5 animais afetados, 3 apresentaram, preferencialmente, sinais cerebrais e 2 a forma paralítica.

Na necropsia foram observadas escoriações na cabeça e hematomas subcutâneos, nos Casos 1 e 5 . Na histologia, as alterações inflamatórias foram semelhantes às observadas em bovinos e sua distribuição apresenta-se no Quadro 8. Ainda foram vistas satelitose e neuroniofagia discretas no córtex cerebral nos Casos 1, 2, 4 e 5, e numerosos esferóides axonais no córtex cerebral, tálamo e tronco encefálico dos Casos 2, 4 e 5. Hemorragias no córtex cerebral e medula espinhal foram observadas nos casos 4 e 5 . Corpúsculos de inclusão foram encontrados em apenas $40 \%(2 / 5)$ dos casos estudados e apareceram com intensidade discreta e com localização no córtex cerebral em um animal e no hipocampo e córtex em outro (Quadro 9). A relação dos sinais clínicos com a localização das lesões no sistema nervoso é observada no Quadro 10.

\section{Raiva em caprinos}

Em caprinos foi estudado um animal em cada um dos 2 surtos observados, sendo um macho e uma fêmea. Todos os animais eram mestiços, sem raça definida. A idade dos animais variou entre 6 meses e 1 ano. Os surtos ocorreram nos meses de março e abril, na região semi-árida da Paraíba, um no sertão (município de São Mamede) e o outro em um município do cariri paraibano (Monteiro). No primeiro surto, de um rebanho de 40 animais adoeceram e morreram 4. Já no outro surto não foi informada a

Quadro 8. Distribuição e intensidade das lesões inflamatórias dos casos de raiva em eqüinos diagnosticados no período de janeiro de 2002 a agosto de 2004 no laboratório de Patologia Veterinária da UFCG, Campus de Patos

\begin{tabular}{|c|c|c|c|c|c|c|c|c|c|c|c|c|c|c|c|}
\hline Caso $n^{\mathrm{o}}$ & $\mathrm{CF}^{\mathrm{a}}$ & $\mathrm{CP}$ & CT & $\mathrm{CO}$ & NB & $\mathrm{TL}$ & $\mathrm{HC}$ & TQ & PT & CE & $\mathrm{BL}$ & $\mathrm{MC}$ & MD & ML & GT \\
\hline 1 & $++^{c}$ & +++ & +++ & + & +++ & +++ & + & +++ & ++ & + & + & + & $\mathrm{Na}^{\mathrm{d}}$ & $\mathrm{Na}$ & $\mathrm{Na}$ \\
\hline $2^{b}$ & +++ & ++ & +++ & ++ & +++ & +++ & ++ & +++ & +++ & ++ & +++ & +++ & $\mathrm{Na}$ & $\mathrm{Na}$ & $\mathrm{Na}$ \\
\hline 3 & + & + & + & - & - & - & - & + & + & - & - & +++ & $\mathrm{Na}$ & $\mathrm{Na}$ & - \\
\hline 4 & +++ & +++ & +++ & ++ & +++ & +++ & + & +++ & ++ & ++ & ++ & + & ++ & + & + \\
\hline 5 & +++ & ++ & +++ & + & +++ & +++ & ++ & +++ & + & + & + & + & + & - & + \\
\hline Total de & $5 / 5$ & $5 / 5$ & $5 / 5$ & $4 / 5$ & $4 / 5$ & $4 / 5$ & $4 / 5$ & $5 / 5$ & $5 / 5$ & $4 / 5$ & $4 / 5$ & $5 / 5$ & $2 / 2$ & $1 / 2$ & $2 / 3$ \\
\hline
\end{tabular}

${ }^{a} \mathrm{CF}=$ córtex frontal, $\mathrm{CP}=$ córtex parietal, $\mathrm{CF}=$ córtex frontal, $\mathrm{CP}=$ córtex parietal, $\mathrm{CT}=$ córtex temporal, $\mathrm{CO}=$ córtex occipital, $\mathrm{NB}=$ núcleos de base, $\mathrm{TL}=$ tálamo, $\mathrm{HC}=$ hipocampo, $\mathrm{TQ}=$ tubérculos quadrigêmeos, $\mathrm{PT}=$ ponte, $\mathrm{CE}=$ cerebelo, $\mathrm{BL}=\mathrm{Bulbo}, \mathrm{MC}=$ medula cervical, $\mathrm{MD}=$ medula dorsal, $\mathrm{ML}=\mathrm{medula}$ lombar e GT= gânglio trigeminal; ${ }^{b}$ Os Casos 2 e 3 pertencem a um mesmo surto; ${ }^{\mathrm{c}}-$ Ausente, + discreta, ++ moderada, +++ acentuada; ${ }^{\mathrm{d}}$ Na $=$ Não avaliado.

Quadro 9. Presença de corpúsculos de inclusão dos casos de raiva em eqüinos diagnosticados no período de janeiro de 2002 a agosto de 2004 no laboratório de Patologia Veterinária da UFCG, Campus de Patos

\begin{tabular}{|c|c|c|c|c|c|c|c|c|c|c|c|c|c|c|c|c|}
\hline Caso $\mathrm{n}^{\mathrm{o}}$ & $\mathrm{CF}^{\mathrm{a}}$ & $\mathrm{CP}$ & $\mathrm{CT}$ & $\mathrm{CO}$ & $\mathrm{CI} / \mathrm{NB}$ & $\mathrm{TL}$ & $\mathrm{HC}$ & TQ & PT & CE & $\mathrm{BL}$ & $\mathrm{MC}$ & MD & ML & GT & $+/-$ \\
\hline 1 & - & - & - & - & - & - & - & - & - & - & - & - & $\mathrm{Na}^{\mathrm{d}}$ & $\mathrm{Na}$ & $\mathrm{Na}$ & - \\
\hline $2^{b}$ & - & - & - & - & - & - & - & - & - & - & - & - & $\mathrm{Na}$ & $\mathrm{Na}$ & $\mathrm{Na}$ & - \\
\hline 3 & - & - & - & - & - & - & - & - & - & - & - & - & $\mathrm{Na}$ & $\mathrm{Na}$ & - & - \\
\hline 4 & $+^{c}$ & - & + & - & - & - & + & - & - & - & - & - & - & - & - & + \\
\hline 5 & - & + & - & + & - & - & - & - & - & - & - & - & - & - & - & + \\
\hline Total de & $1 / 5$ & $1 / 5$ & $1 / 5$ & $1 / 5$ & $0 / 5$ & $0 / 5$ & $1 / 5$ & $0 / 5$ & $0 / 5$ & $0 / 5$ & $0 / 5$ & $0 / 5$ & $0 / 2$ & $0 / 2$ & $0 / 3$ & $2 / 5$ \\
\hline
\end{tabular}

positivos /estudados

${ }^{a} \mathrm{CF}=$ córtex frontal, $\mathrm{CP}=$ córtex parietal, $\mathrm{CF}=$ córtex frontal, $\mathrm{CP}=$ córtex parietal, $\mathrm{CT}=$ córtex temporal, $\mathrm{CO}=$ córtex occipital, $\mathrm{NB}=$ núcleos de base, $\mathrm{TL}=$ tálamo, $\mathrm{HC}=$ hipocampo, $\mathrm{TQ}=$ tubérculos quadrigêmeos, $\mathrm{PT}=$ ponte, $\mathrm{CE}=$ cerebelo, $\mathrm{BL}=\mathrm{Bulbo}, \mathrm{MC}=$ medula cervical, $\mathrm{MD}=\mathrm{medula}$ dorsal, $\mathrm{ML}=\mathrm{medula}$

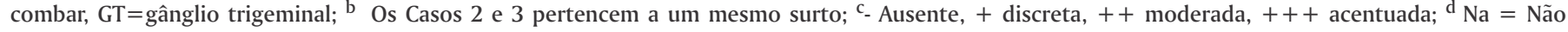
avaliado. 
Quadro 10. Sinais clínicos relacionados com a lesão na região do sistema nervoso central em 5 equiinos com raiva diagnosticados no período de janeiro de 2002 a agosto de 2004 no HV da UFCG, Campus de Patos

\begin{tabular}{|c|c|c|c|c|c|c|c|c|}
\hline \multirow[t]{2}{*}{ Caso $n^{\circ}$} & \multicolumn{2}{|l|}{ Cérebro } & \multicolumn{2}{|c|}{ Tronco encefálico } & \multicolumn{2}{|c|}{ Cerebelo } & \multicolumn{2}{|c|}{ Medula espinhal } \\
\hline & Sinais clínicos & Lesões & Sinais clínicos & Lesões & Sinais clínicos & Lesões & Sinais clínicos & Lesões \\
\hline 1 & $+++^{a}$ & +++ & ++ & +++ & - & + & + & $\mathrm{Na}^{\mathrm{C}}$ \\
\hline $2^{b}$ & - & ++ & - & +++ & - & ++ & +++ & +++ \\
\hline 3 & - & + & - & + & - & - & +++ & +++ \\
\hline 4 & +++ & +++ & ++ & +++ & - & ++ & + & + \\
\hline 5 & +++ & +++ & ++ & ++ & + & + & + & + \\
\hline Total de & $3 / 5$ & $5 / 5$ & $3 / 5$ & $5 / 5$ & $1 / 5$ & $4 / 5$ & $5 / 5$ & $4 / 4$ \\
\hline
\end{tabular}

positivos estudados

a Ausente, + discreta ++ moderada, +++ acentuada; ${ }^{\mathrm{b}}$ Os Casos 12 e 13 pertencem a um mesmo surto; ${ }^{\mathrm{c}} \mathrm{Na}=$ Não avaliado.

frequiência da doença. Em todos os surtos os animais não eram vacinados com vacina anti-rábica. Os caprinos eram criados a campo, sendo recolhidos à noite e alimentados com pastagem nativa. No surto ocorrido no município de Monteiro a raiva era endêmica na região e na época o produtor mencionou a ocorrência de morcegos hematófagos. No outro surto ocorreu, também, à morte de bovinos e eqüinos, que não tinham sido vacinados.

A evolução clínica da doença, informada num caso, foi de 35 dias e os sinais clínicos nos caprinos estão no Quadro 11. Quanto à intensidade dos sinais clínicos de raiva referentes a diferentes regiões do SNC dos caprinos, o Caso 1 apresentou, principalmente, sinais clínicos de origem cerebral e os outros sinais de origem no tronco encefálico e medula espinhal (Quadro 12).

Quadro 11. Sinais clínicos de raiva em caprinos e ovinos em casos diagnosticados no período de janeiro de 2002 a agosto de 2004 no HV da UFCG, Campus de Patos

\begin{tabular}{|c|c|c|c|c|c|c|}
\hline \multirow[t]{2}{*}{ Sinais clínicos } & \multicolumn{2}{|c|}{ Caprinos } & \multicolumn{4}{|c|}{ Ovinos } \\
\hline & Caso 1 & Caso 2 & Caso 1 & Caso $2^{\mathrm{a}}$ & Caso & Caso 4 \\
\hline \multicolumn{7}{|l|}{ Cérebro } \\
\hline Apatia & $++^{b}$ & - & + & - & - & - \\
\hline Cegueira & + & - & - & - & - & - \\
\hline Convulsões periódicas & + & - & - & - & - & - \\
\hline Movimentos de pedalagem & - & + & - & - & - & - \\
\hline Mudanças de atitude & - & - & + & - & - & - \\
\hline Pressão da cabeça contra objetos & os + & - & - & - & - & - \\
\hline \multicolumn{7}{|l|}{ Tronco encefálico } \\
\hline Ataxia & + & - & - & - & - & - \\
\hline Diminuição do reflexo pupilar & + & - & - & - & - & - \\
\hline Flacidez da língua & - & - & - & - & + & + \\
\hline Rotação da cabeça & + & - & - & - & - & - \\
\hline Salivação & - & - & + & - & - & - \\
\hline \multicolumn{7}{|l|}{ Cerebelo } \\
\hline Opistótono & - & + & - & - & - & - \\
\hline Perda de equilíbrio & + & - & + & - & - & - \\
\hline Tremores de intenção & - & - & - & - & - & + \\
\hline \multicolumn{7}{|l|}{ Medula espinhal } \\
\hline Decúbito esternal & - & - & + & - & - & - \\
\hline Decúbito lateral & - & + & - & + & + & + \\
\hline Incoordenação & - & + & - & + & - & + \\
\hline Paralisia de membros & - & - & - & + & + & - \\
\hline Paresia de membros & - & - & - & - & - & + \\
\hline
\end{tabular}

a - Ausente, + presente; ${ }^{\mathrm{b}}$ Os Casos 2, 3 e 4 pertencem a um mesmo surto.
Quadro 12. Intensidade dos sinais clínicos de raiva referentes a diferentes regiões do SNC dos casos de raiva em caprinos e ovinos diagnosticados no período de janeiro de 2002 a agosto de 2004 no HV da UFCG, Campus de Patos

\begin{tabular}{cccccc}
\hline Espécie & № Caso & Cérebro & Tronco encefálico & Cerebelo & Medula espinhal \\
\hline Caprinos & Caso 1 & $+++^{\mathrm{a}}$ & ++ & - & - \\
& Caso 2 & - & + & ++ & ++ \\
Ovinos & Caso 1 & ++ & ++ & + & - \\
& Caso 2 & - & + & - & +++ \\
& Caso 3 & - & +++ & - & ++ \\
& Caso 4 & - & ++ & + & +++ \\
\multicolumn{7}{c}{ Total de } & $2 / 6$ & $6 / 6$ & $3 / 3$ & $4 / 4$
\end{tabular}

positivos /estudados

a - Ausente, + discreta, ++ moderada, +++ acentuada.

b Os Casos 2, 3 e 4 pertencem a um mesmo surto.

Na necropsia, não foram observadas lesões. Os achados histológicos foram caracterizados por lesões inflamatórias (acúmulo perivascular de células mononucleares, gliose e meningite) (Quadro 13). No Caso 1 foi observado ainda satelitose, neuronofagia e em diversas áreas do tronco encefálico foram encontrados esferóides axonais e elipsóides de mielina com restos de axônios ou macrófagos, evidenciando um processo de degeneração tipo Walleriana em conseqüência da morte neuronal observada no diencéfalo e mesencéfalo. A relação dos sinais clínicos com a lesão em diferentes regiões do SNC é observada no Quadro 14.

\section{Raiva em ovinos}

Foram diagnosticados 2 surtos de raiva em ovinos, ambos no sertão da Paraíba, na região semi-árida. Em um dos surtos (Caso 1) a doença foi aparentemente transmitida por mordida de cães. Neste surto, que ocorreu em ovinos da raça Santa Inês no mês de março de 2003, no município de São Mamede, além de ovinos estiveram envolvidas outras espécies como, cães, bovinos, caprinos, eqüinos e asininos. 0 proprietário informou que o cão havia brigado e matado uma raposa e depois adoeceu e mordeu os animais no curral, em seguida adoeceu um equiino, um asinino, um bovino, um caprino e por último um ovino. Não foram informados a idade e o sexo do animal afetado, nem o número de animais no rebanho e animais afetados.

Outro surto ocorreu no mês de agosto de 2004, no municí- 
Quadro 13. Distribuição e intensidade das lesões inflamatórias dos casos de raiva em caprinos e ovinos diagnosticados no período de janeiro de 2002 a agosto de 2004 no laboratório de Patologia Veterinária da UFCG, Campus de Patos

\begin{tabular}{|c|c|c|c|c|c|c|c|c|c|c|c|c|c|c|c|}
\hline Espécie & Caso & $\mathrm{CF}^{\mathrm{a}}$ & $\mathrm{CP}$ & CT & $\mathrm{CO}$ & NB & $\mathrm{TL}$ & $\mathrm{HC}$ & TQ & PT & CE & $\mathrm{BL}$ & $\mathrm{MC}$ & MD & ML \\
\hline \multirow[t]{3}{*}{ Caprinos } & Caso 1 & $+++{ }^{b}$ & +++ & +++ & ++ & +++ & +++ & +++ & +++ & ++ & ++ & $\mathrm{Na}^{\mathrm{d}}$ & + & + & + \\
\hline & Caso 2 & + & ++ & ++ & + & ++ & ++ & - & +++ & ++ & ++ & ++ & +++ & +++ & ++ \\
\hline & Caso 1 & + & + & ++ & + & ++ & + & + & ++ & ++ & +++ & - & $\mathrm{Na}$ & $\mathrm{Na}$ & $\mathrm{Na}$ \\
\hline \multirow[t]{3}{*}{ Ovinos } & Caso $2^{\mathrm{C}}$ & - & - & - & - & - & - & - & ++ & + & - & +++ & +++ & $\mathrm{Na}$ & + \\
\hline & Caso 3 & + & - & - & - & - & + & - & + & + & - & + & +++ & + & + \\
\hline & Caso 4 & + & + & - & - & + & ++ & + & ++ & ++ & + & ++ & +++ & +++ & + \\
\hline Total de & & $5 / 6$ & $4 / 6$ & $3 / 6$ & $3 / 6$ & $4 / 6$ & $5 / 6$ & $3 / 6$ & $6 / 6$ & $6 / 6$ & $4 / 7$ & $4 / 5$ & $5 / 5$ & $4 / 4$ & $5 / 5$ \\
\hline
\end{tabular}

positivos/estudados

$\bar{a} \mathrm{CF}=$ córtex frontal, $\mathrm{CP}=$ córtex parietal, $\mathrm{CF}=$ córtex frontal, $\mathrm{CP}=$ córtex parietal, $\mathrm{CT}=$ córtex temporal, $\mathrm{CO}=$ córtex occipital, $\mathrm{NB}=$ núcleos de base, $\mathrm{TL}=$ tálamo, $\mathrm{HC}=$ hipocampo, $\mathrm{TQ}=$ tubérculos quadrigêmeos, $\mathrm{PT}=$ ponte, $\mathrm{CE}=$ cerebelo, $\mathrm{BL}=\mathrm{Bulbo}, \mathrm{MC}=$ medula cervical, $\mathrm{MD}=\mathrm{medula}$ dorsal, $\mathrm{ML}=\mathrm{medula}$ lombar; ${ }^{\mathrm{b}}$ - Ausente, + discreta, ++ moderada, +++ acentuada; ${ }^{c}$ Os Casos 2,3 e 4 pertencem a um mesmo surto; ${ }^{d}$ Na $=$ Não avaliado.

Quadro 14. Presença de corpúsculos de inclusão dos casos de raiva em caprinos e ovinos diagnosticados no período de janeiro de 2002 a agosto de 2004 no HV da UFCG, Campus de Patos

\begin{tabular}{|c|c|c|c|c|c|c|c|c|c|c|c|c|c|c|c|c|}
\hline Espécie & Caso & $\mathrm{CF}^{\mathrm{a}}$ & $\mathrm{CP}$ & CT & $\mathrm{CO}$ & NB & $\mathrm{TL}$ & $\mathrm{HC}$ & TQ & PT & $\mathrm{CE}$ & $\mathrm{BL}$ & $\mathrm{MC}$ & MD & ML & $+/-$ \\
\hline \multirow[t]{3}{*}{ Caprinos } & Caso 1 & $++^{b}$ & + & + & - & - & - & - & - & - & + & - & - & - & - & + \\
\hline & Caso 2 & ++ & ++ & +++ & - & - & - & + & + & + & +++ & - & - & - & - & $\begin{array}{c}+ \\
100\end{array}$ \\
\hline & Caso 1 & - & - & - & - & - & - & - & - & - & - & - & $\mathrm{Na}^{\mathrm{d}}$ & $\mathrm{Na}$ & $\mathrm{Na}$ & - \\
\hline \multirow[t]{3}{*}{ Ovinos } & Caso $2^{\mathrm{C}}$ & - & - & ++ & - & - & - & - & + & + & + & - & + & $\mathrm{Na}$ & + & + \\
\hline & Caso 3 & ++ & + & - & - & - & - & ++ & + & + & +++ & + & ++ & + & - & + \\
\hline & Caso 4 & - & - & - & - & + & - & - & + & + & ++ & - & - & - & - & + \\
\hline Total de & & $3 / 6$ & $3 / 6$ & $3 / 6$ & $0 / 6$ & $1 / 6$ & $0 / 6$ & $2 / 6$ & $4 / 6$ & $4 / 6$ & $5 / 6$ & $1 / 6$ & $2 / 5$ & $1 / 4$ & $1 / 5$ & 75,0 \\
\hline
\end{tabular}

a $\mathrm{CF}=$ córtex frontal, $\mathrm{CP}=$ córtex parietal, $\mathrm{CF}=$ córtex frontal, $\mathrm{CP}=$ córtex parietal, $\mathrm{CT}=$ córtex temporal, $\mathrm{CO}=$ córtex occipital, $\mathrm{NB}=$ núcleos de base, $\mathrm{TL}=$ tálamo, $\mathrm{HC}=$ hipocampo, $\mathrm{TQ}=$ tubérculos quadrigêmeos, $\mathrm{PT}=$ ponte, $\mathrm{CE}=$ cerebelo, $\mathrm{BL}=\mathrm{Bulbo}, \mathrm{MC}=\mathrm{medula}$ cervical, $\mathrm{MD}=\mathrm{medula}$ dorsal, $\mathrm{ML}=\mathrm{medula}$ lombar; ${ }^{\mathrm{b}}$ - Ausente, + discreta, ++ moderada, +++ acentuada; ${ }^{c}$ Os Casos 2,3 e 4 pertencem a um mesmo surto; ${ }^{\mathrm{d}}$ Na $=$ Não avaliado.

pio de Santa Terezinha, em um grupo de ovinos da raça Santa Inês, de 5-12 meses de idade, que estavam sendo alimentados com cama de frango e não tinham sido vacinados contra raiva. 0 rebanho era de 80 animais, dos quais adoeceram e morreram $6(7,5 \%)$. Neste surto não foi determinada a fonte de infecção, pois o proprietário não soube informar sobre a presença de morcegos hematófagos nem de raposas.

A evolução clínica da doença nos ovinos do surto ocorrido em Santa Terezinha foi de 3-5 dias e no outro surto não foi informada a evolução clínica. Os sinais clínicos são observados no Quadro 11. Os sinais clínicos referentes a cada região do SNC e sua relação com a distribuição das lesões histológicas são apresentados no Quadro 12.

Na necropsia não foram observadas alterações significativas. Na histopatologia os achados histológicos foram caracterizados por acúmulo perivascular de células mononucleares, gliose e meningite (Quadro 13) e por corpúsculos de inclusão identificados em 3 dos 4 ovinos (Quadro 14). A relação dos sinais clínicos com a localização das lesões em diferentes regiões do SNC é observada na Quadro 15.

Quadro 15. Sinais clínicos correlacionados com a lesão na região do sistema nervoso central de caprinos e ovinos diagnosticados no período de janeiro de 2002 a agosto de 2004 no laboratório de Patologia Veterinária da UFCG, Campus de Patos

\begin{tabular}{|c|c|c|c|c|c|c|c|c|c|}
\hline \multirow[t]{2}{*}{ Espécie } & \multirow[t]{2}{*}{ Caso } & \multicolumn{2}{|c|}{ Cérebro } & \multicolumn{2}{|c|}{ Tronco encefálico } & \multicolumn{2}{|c|}{ Cerebelo } & \multicolumn{2}{|c|}{ Medula espinhal } \\
\hline & & Sinais clínicos & Lesões & Sinais clínicos & Lesões & Sinais clínicos & Lesões & Sinais clínicos & Lesões \\
\hline \multirow[t]{2}{*}{ Caprina } & Caso 1 & $+++^{b}$ & +++ & ++ & +++ & - & + & - & + \\
\hline & Caso $2^{\mathrm{a}}$ & - & + & ++ & ++ & ++ & ++ & ++ & +++ \\
\hline \multirow[t]{4}{*}{ Ovina } & Caso 1 & ++ & + & ++ & ++ & + & +++ & - & $\mathrm{Na}^{\mathrm{c}}$ \\
\hline & Caso $2^{\mathrm{b}}$ & - & + & + & ++ & - & + & +++ & ++ \\
\hline & Caso 3 & - & + & +++ & + & - & + & ++ & +++ \\
\hline & Caso 4 & - & + & ++ & ++ & + & + & +++ & +++ \\
\hline Total de & & $2 / 6$ & $6 / 6$ & $6 / 6$ & $6 / 6$ & $3 / 6$ & $6 / 6$ & $4 / 6$ & $5 / 5$ \\
\hline
\end{tabular}

positivos/estudados

a Os casos 2,3 e 4 pertencem a um mesmo surto; ${ }^{\text {b }}$ - Ausente, + discreto, ++ moderado e +++ acentuado; ${ }^{\mathrm{c}} \mathrm{Na}=\mathrm{Não}$ avaliado. 


\section{DISCUSSÃO}

A frequiência da raiva em bovinos na região semi-árida é alta, sendo não só a principal doença do sistema nervoso, mas a mais freqüientemente diagnosticada dentre todas as enfermidades (Quadro 1). Considerando-se que a população bovina da Paraíba é de 918.262 cabeças e que há uma mortalidade anual de 5\% do rebanho, pode-se estimar que morram no Estado 45.913 bovinos anualmente. Como a freqüência da raiva foi de $18,75 \%$ de todos os diagnósticos realizados pelo HV durante o período, pode estimar-se que $18,75 \%$ das mortes anuais de bovinos na Paraíba ocorrem por raiva, o que representa 8.609 bovinos mortos. Essa mortalidade por raiva é bem superior à observada em outros Estados. No Rio Grande do Sul, que tem uma população de 13 milhões de bovinos, o percentual de animais mortos por raiva é de $2 \%$ (Riet-Correa et al. 1999) a 2,5\% (Sanches et al. 2000); fazendo-se os cálculos utilizados para a Paraíba, a raiva causa a morte de 13.000 a 16.250 bovinos ao ano. No Mato Grosso do Sul, com uma população de 23 milhões de bovinos e uma freqüência de diagnósticos de raiva de 13\% (Lemos 2005) pode-se estimar que morram 149.500 bovinos anualmente. Se somar os dados dos 3 Estados chega-se a uma população de aproximadamente 40 milhões de bovinos, dos quais aproximadamente 172.859 morrem anualmente por raiva. Esse número pode ser ainda maior, já que no Mato Grosso do Sul, no número de animais mortos por raiva, $o$ autor não considerou como casos de raiva 131 casos $(9,16 \%$ dos casos) com diagnóstico histológico de meningoencefalite não supurativa, sem corpúsculos de inclusão (Lemos 2005). Não foram encontrados dados publicados de outros Estados sobre a freqüência das diferentes doenças dos bovinos, mas se extrapolarmos esses dados para todo o Brasil, com uma população de 195 milhões de bovinos, pode-se estimar que no país morram, anualmente, 842.688 bovinos. Essas estimativas são muito superiores às anteriores, que mencionam 30.000 (Rodrigues da Silva et al. 2000) a 40.000 (Heinemann et al. 2002) bovinos mortos anualmente. A maior frequiência de raiva em bovinos na Paraíba em relação ao Mato Grosso do Sul e Rio Grande do Sul deve-se, provavelmente, entre outras causas, ao fato de que nesses estados são realizadas campanhas de controle de morcegos, o que não acontece na Paraíba.

Considerando a população de eqüinos em relação à população de bovinos (Quadro 1) sugere-se que, no semi-árido da Paraíba, a raiva em eqüinos é tão freqüiente quanto em bovinos (Quadro 1); no entanto, a doença mais freqüiente nesta espécie não é a raiva e sim a intoxicação por Crotalaria retusa (Nobre et al. 2004).

Pelos dados obtidos neste trabalho, a freqüência da raiva em caprinos e ovinos na região semi-árida da Paraíba é menor do que a observada em bovinos e eqüinos. Esta situação pareceria ser semelhante ao que ocorre em outros Estados do Brasil, onde a raiva de bovinos é muito freqüente, enquanto que a raiva de ovinos tem sido observada somente no Rio Grande do Sul (RietCorrea et al. 1983, Cláudio Barros 2003, dados não publicados) e não há publicações sobre raiva em caprinos. A menor freqüência nessas espécies é provavelmente devida a menor frequiência de ataques por morcegos, pois não há evidências de que os pequenos ruminantes sejam mais resistentes à doença. No en- tanto, deve-se considerar que o rebanho de pequenos ruminantes no Brasil é de 14.556 .484 ovinos e 9.581.653 caprinos (IBGE 2003), muito menor que a de bovinos, de 195 milhões de cabeças. A maior concentração de ovinos é encontrada no Nordeste e no Rio Grande do Sul, e a maior concentração de caprinos no Nordeste, no entanto, considera-se que a caprinocultura e a ovinocultura estão em expansão em outras regiões do País é provável que haja aumento no número de surtos de raiva nessas espécies.

Em bovinos foi observada maior prevalência da raiva em animais jovens, com menos de 2 anos (Fig.2). É provável que esse fato seja devido à menor imunidade dos animais jovens, que pode ser devida à não realização da revacinação $30-40$ dias após a primeira vacinação, ou a um retardo na idade da primovacinação, que deve ser realizada aos 3-4 meses de idade. Por outro lado é evidente que na medida em que os animais são revacinados anualmente a sua imunidade aumenta. A mesma situação é observada no Mato Grosso do Sul onde há também uma maior prevalência em animais jovens (Langohr et al. 2003, Mori et al 2004, Lemos 2005). Não pode ser descartada a possibilidade de que a maior prevalência da raiva em animais jovens seja devida, também, em parte, à sua maior susceptibilidade à infecção viral (Tierkel 1975), por serem mais atacados por morcegos hematófagos, ou ainda por receberem uma dose infectante proporcionalmente maior do que os animais adultos.

Em relação à época de ocorrência da enfermidade, foram observados surtos em todos os meses, exceto fevereiro, setembro e dezembro; no entanto, a maior freqüiência foi entre os meses de março e agosto, durante os quais foram observados 28 surtos de um total de 32, nas diferentes espécies (Fig.1). Na região, essa época coincide com a segunda metade do período de chuvas (que normalmente vai de janeiro a abril) e os primeiros meses da seca. Esses dados sugerem que a vacinação contra a raiva deve ser realizada nos meses de janeiro ou fevereiro, antes da época de maior incidência da doença. No Mato Grosso do Sul, a época de maior incidência é o outono (abril a junho) (Mori et al. 2004) e em Minas Gerais e São Paulo a maior incidência é de abril a agosto (Silva et al. 2001).

Um fato importante é que todos os surtos ocorreram em animais não vacinados, com exceção de um surto em bovinos que afetou animais de até 1 ano e meio de idade e um surto que afetou um cavalo adulto que havia sido vacinado há 5 meses. Por outro lado, todos os surtos foram controlados após a vacinação dos animais em risco, sendo que em um desses surtos morreram ainda 3 animais após a vacinação. Esses dados sugerem a eficácia das vacinas empregadas na região; portanto, a presença de animais não imunizados se deve a falhas no programa de vacinação utilizado e não à incapacidade das vacinas em imunizar.

A ocorrência da doença em animais jovens vacinados, em um surto, deve-se provavelmente a que esses animais não tinham sido revacinados após a primovacinação. A morte de alguns animais após a vacinação em outro surto deve-se ao fato desses animais estarem incubando à doença no momento da vacinação. Falhas na vacinação de raiva têm sido descritas anteriormente no Brasil (Montaño et al. 1987, Langohr et al. 2003). Em alguns casos a falha ocorre somente nos animais jovens, com menor número de vacinações e em outras em animais re- 
centemente vacinados que, provavelmente, estavam incubando a doença. Neste último caso devemos considerar que a raiva, em infecções espontâneas, tem um período de incubação de 30-60 dias (Mori et al. 2004).

Apesar da menor freqüência da raiva em ovinos e caprinos do que em bovinos e eqüinos (Quadro 1), na atual situação da região semi-árida, onde a raiva é endêmica em diversas regiões, a ocorrência de raiva em pequenos ruminantes sugere que estas espécies sejam, também, vacinadas anualmente, pelo menos em regiões onde tenham ocorrido, recentemente, casos de raiva em bovinos ou eqüinos.

Apesar das dificuldades em estabelecer a fonte de infecção nos casos de raiva na região Nordeste, parece que a maioria é transmitida por morcegos hematófagos. Isto por que no Brasil a variante de vírus isolada em bovinos é a mesma isolada de Desmodus rotundus (Heinemann et al. 2002). Também na Paraíba a variante isolada em bovinos e equiinos foi semelhante à de $D$. rotundus (Gomes 2004). No entanto, deve-se considerar que no semi-árido da Paraíba, onde a raiva é endêmica, foi isolado vírus rábico em 12 de 299 raposas (Dusicyon vetulus) estudadas, demonstrado que a raposa do Nordeste é um reservatório silvestre importante do vírus da raiva (Gomes 2004). Um dos surtos em ovinos foi aparentemente associado a um cão que tinha sido mordido anteriormente por uma raposa. Para Radostits et al. (2002), em ovinos, a raiva transmitida por carnívoros ocorre, freqüientemente, em vários animais de uma vez, devido à facilidade com que certo número desses ovinos pode ser mordido por um cão ou raposa.

Os sinais clínicos predominantes em bovinos foram da forma paralítica, já que todos os 25 casos apresentaram sinais de lesões da medula, no entanto 23 dos 25 casos apresentaram, também, sinais de lesões do tronco encefálico, 12 casos apresentaram sinais de lesões cerebelares e 10 de lesões cerebrais (Quadro 6). Essa variação nos sinais clínicos evidencia as dificuldades para o diagnóstico clínico presuntivo da raiva. $\mathrm{O}$ quadro mais característico é o de uma paralisia progressiva com sinais preferentemente medulares e comprometimento variável do tronco encefálico. No entanto, alguns animais podem mostrar sinais preferentemente cerebrais, semelhantes aos de outras doenças que afetam o SNC de bovinos no Brasil, como a poliencefalomalacia e a encefalite por herpesvírus bovino-5. Deve ser chamada a atenção para o fato de que essa variação nos sinais clínicos, associado à alta freqüência da raiva no Brasil, faz com que esta deva sempre ser considerada no diagnóstico diferencial das doenças do SNC que cursam com curso agudo ou subagudo. $\mathrm{O}$ principal fato sugestivo de raiva é o de uma lesão difusa do SNC afetando medula, tronco encefálico, cerebelo e cérebro. Os sinais clínicos observados concordam com a distribuição das lesões no SNC (Quadro 3), que foram mais freqüentes na medula, mas ocorreram também nas outras regiões. Macruz et al. (1977) encontraram, também, lesões mais intensas na medula espinhal com menor número de bovinos apresentando lesões no bulbo, corno de Ammon e cerebelo, enquanto que Langohr et al. (2003) observaram que o tronco encefálico, o cerebelo e a medula cervical foram mais afetados que o tálamo e o telencéfalo, incluindo o hipocampo; nesse trabalho não foram avaliadas a medula dorsal e lombar.
Já em eqüinos, em 3 animais (Casos 1, 4 e 5) os sinais clínicos e as lesões histológicas afetaram, principalmente, o cérebro com lesões menos severas no tronco encefálico e lesões discretas na medula espinhal, apresentando tanto agressividade quanto depressão profunda e outros sinais cerebrais. Já nos Casos 2 e 3, as lesões foram mais evidentes no tronco encefálico e medula com sinais preferentemente de alterações da marcha. Considerando a variação dos sinais clínicos podemos concluir que a principal característica dos sinais clínicos da raiva em eqüinos é a de evidenciarem lesões difusas do SNC, afetando tanto a medula, quanto o tronco encefálico e o cérebro. No semi-árido da Paraíba, a primeira doença que deve ser considerada no diagnóstico diferencial da raiva é a intoxicação por Crotalaria retusa, que é a enfermidade mais freqüente do SNC de eqüinos caracterizada, principalmente, por sinais de origem cerebral e do tronco encefálico (Nobre et al. 2004). A única diferença é que na intoxicação por $C$. retusa há sinais de insuficiência hepática e que alguns cavalos apresentam histórico de emagrecimento progressivo. Exames bioquímicos da função hepática e biopsia hepática são importantes para o diagnóstico de encefalopatia hepática. Outra doença importante, que tem sido diagnosticada na região, é a mielite eqüina causada por herpesvírus eqüino-1 (RietCorrea et al. 2003), que, nos casos observados no semi-árido tem se caracterizado por sinais clínicos agudos de lesão medular, com paralisia e perda de sensibilidade; nestes casos a lesão histológica caracterizada, principalmente, por vasculite e presença de infartos na medula são características. $O$ tétano é outra doença freqüente no semi-árido, mas apresenta sinais característicos e ausência de lesões histológicas. A raiva também deve ser diferenciada da leucoencefalomalacia, que apresenta, principalmente, sinais cerebrais, mas, também, do tronco encefálico; nesta doença, em geral, o curso clínico é de até 24 horas, mas em um caso na Paraíba o curso clínico foi de 72 horas (RietCorrea et al. 2003). Outras doenças como a encefalomielite viral dos eqüinos e a mieloencefalite por protozoário não têm sido diagnosticados na Paraíba.

Em relação aos sinais clínicos e distribuição das lesões no SNC de ovinos e caprinos pode ser observado que na maioria dos animais os sinais clínicos mais marcados estavam associados a lesões da medula e tronco encefálico, mas um desses animais mostrou também sinais causados por lesões cerebrais e sinais associados a lesões cerebelares. Por outro lado, no Caprino 1 tanto os sinais quanto as lesões eram mais marcadas no cérebro. A característica de causar sinais clínicos associados a lesões difusas do SNC é importante para o diagnóstico presuntivo de raiva em pequenos ruminantes. Essa variação dos sinais clínicos faz com que a raiva possa ser confundida com outras doenças freqüientes do sistema nervoso central de pequenos ruminantes. Na região semi-árida as doenças mais freqüientemente observadas em pequenos ruminantes são a polioencefalomalacia (Lima et al. 2005), os abscessos cerebrais e os traumatismos. A polioencefalomalacia, por causar sinais cerebrais, assim como sinais cerebelares e do tronco encefálico pode ser facilmente confundida com casos de raiva com lesões predominantes cerebrais, como as do Caso 1 . Os abscessos e os traumatismos se diferenciam da raiva por causar lesões focais. A raiva em ovinos pode também ser confundida com o botulismo; principalmente 
em animais com a forma paralítica, como ocorreu no surto observado em ovinos que estavam ingerindo cama de frango em que os animais apresentavam um curso clínico de 3-5 dias e dois deles chegaram ao HV em decúbito permanente com paralisia flácida. Essa paralisia flácida é devida a que as lesões da medula localizam-se, preferentemente, na porção ventral da sustância cinzenta. Surtos de botulismo já foram descritos, na região semiárida, em ovinos alimentados com cama de frango (Riet-Correa et al. 2003).

Neste estudo, a evolução clínica em bovinos e eqüinos foi de 2-8 dias, com média de 4,7 dias para bovinos e de 6 dias e meio para os equiinos, sendo que os eqüinos que apresentaram sinais clínicos mais intensos de origem cerebral, tiveram a evolução clínica mais longa que o que apresentou sinais medulares, provavelmente por que o decúbito permanente acelera o curso clínico da doença, principalmente na região semi-árida onde as condições ambientais (calor e insolação) são extremamente adversas para animais que permanecem no meio ambiente. Em ovinos, o curso clínico dos 3 animais do Surto 2 foi de 3-5 dias, enquanto que no único caprino que foi informado o curso clínico foi de 35 dias. Essas diferenças poderiam, pelo menos em parte, ser devidas a diferenças entre as espécies; em ovinos e caprinos inoculados experimentalmente no músculo masseter o curso clínico foi de 1-2 dias para os ovinos e 3-5 dias para os caprinos (Gomes 2004).

Em bovinos as únicas lesões macroscópicas associadas à raiva foram a bexiga distendida, observada em 4 animais, e a ampola retal distendida e repleta de fezes, em 2 desses animais, que ocorrem devido às lesões localizadas na região sacral da medula espinhal. Não foram observadas outras lesões mencionadas por outros autores, como a pneumonia por aspiração e a presença de corpos estranhos no estômago ou ferimentos por automutilação (Riet-Correa et al. 1983, Swanepoel 1994, Mori et al 2004, Lemos 2005). Em eqüiinos, as lesões encontradas em animais com sinais cerebrais, foram escoriações na cabeça e hematomas subcutâneos observadas nos Casos 1 e 5, que ocorreram por traumatismos ao baterem contra cercas ou outros objetos.

As lesões histológicas caracterizadas por meningoencefalomielite e ganglioneurite linfocitárias, com gliose focal ou difusa, são características da raiva e foram semelhantes nas 4 espécies. A única diferença observada entre as espécies é que as lesões dos eqüinos e as de um caprino foram, em geral, mais acentuadas que as dos outras espécies. Chama a atenção a presença de lesões degenerativas em diversas áreas do tronco encefálico no Caprino 1, caracterizadas por esferóides axonais e elipsóides de mielina com restos de axônios ou macrófagos, evidenciando um processo de degeneração tipo walleriana, em conseqüência da morte neuronal observada no diencéfalo e mesencéfalo. Essas lesões ocorreram provavelmente pelo longo curso clínico da enfermidade neste animal, que foi de 35 dias.

Necrose neuronal, acompanhada de neuroniofagia e satelitose, não foi observada nos 23 bovinos estudados histologicamente, mas ocorreu em 4 dos 5 eqüinos estudados, 3 dos quais apresentaram também esferóides axonais, demonstrando que as lesões da raiva em eqüinos são mais graves e incluem lesões degenerativas e necróticas não observadas em bovinos. Nos bovinos as lesões mais acentuadas foram observadas nos animais que tiveram curso clínico mais prolongado.

A distribuição das lesões histológicas, nas 4 espécies, em geral, estiveram de acordo com os sinais clínicos (Quadros 4, 8 e 13) comprovando que a raiva é uma doença difusa do SNC com distribuição das lesões e sinais clínicos variáveis. Essa informação é importante para o diagnóstico da raiva, para o qual, além de um exame clínico cuidadoso é necessário de estudar histologicamente diversas áreas do SNC, incluindo a medula. $\mathrm{O}$ estudo histológico sistemático do SNC é importante, também, para o diagnóstico diferencial da raiva com outras doenças do SNC.

Em bovinos, histologicamente, foram observados corpúsculos de inclusão em $87 \%$ (20/23) dos casos. Essa freqüência é maior que a observada no Mato Grosso do Sul que foi de $68 \% \mathrm{em}$ 25 bovinos (Langohr et al. 2003) e de 48,1\% em 27 (Lemos 2005). Outros autores mencionam que até $30 \%$ dos casos de raiva não apresentam os corpúsculos e que certas cepas do vírus não produzem corpúsculos de inclusão (Braund et al. 1987, Jubb \& Huxtable 1993). No Brasil, em 20 bovinos inoculados com vírus rábico isolado de bovinos, que foram sacrificados na fase agônica, não foram encontrados corpúsculos de inclusão (Macruz et al. 1977).

A freqüência e intensidade dos corpúsculos foram maiores nos animais que apresentaram curso clínico de mais de 4 dias; no entanto, foram mais freqüentes em áreas com reação inflamatória discreta, ou mesmo sem reação inflamatória, do que em áreas com inflamação severa. Achados semelhantes são mencionados por outros autores (Braund et al. 1987, Jubb \& Huxtable 1993, Langohr et al. 2003). Esse fato sugere que o diagnóstico histológico, assim como o diagnóstico por imunofluorescência, é mais fácil em animais com curso clínico mais prolongado. Com base neste fato é recomendável deixar evoluir a enfermidade antes de eutanasiar o animal ou deixar que este morra espontaneamente.

Em relação à distribuição dos corpúsculos de inclusão em bovinos, eles foram mais freqüientes no cerebelo, seguidos pela ponte bulbo e tubérculo quadrigêmio anterior (Quadro 5). Esses resultados confirmam observações anteriores que mencionam a maior freqüência de corpúsculos de inclusão no cerebelo (Langohr et al. 2003). No entanto, dos 20 bovinos que apresentaram corpúsculos de inclusão, em 3 não foram encontrados corpúsculos no cerebelo. Esses resultados sugerem que, apesar do cerebelo ser a região recomendada para a realização do exame de imunofluorescência, amostras de outras regiões do SNC devem ser enviadas ao laboratório para repetir o exame no caso do cerebelo resultar negativo. Bingham \& Merwe (2002) observando a positividade para a prova de imunofluorescência em diferentes regiões do SNC demonstraram que o tronco encefálico, preferentemente o tálamo, é a principal região de escolha para o exame; o cerebelo, hipocampo e diferentes partes do cérebro de animais com raiva resultaram negativos para essa técnica. Diferentemente ao observado por esses autores, neste estudo, o tálamo pareceria não ser uma região preferencial para o exame de raiva em bovinos, já que foram encontrados corpúsculos de Negri no tálamo em somente 35\% (7/20) dos casos. Essas diferenças poderiam ser devidas a diferenças entre cepas de vírus. É 
importante destacar que o trabalho de Bingham \& Merwe (2002) foi realizado na África do Sul, em diferentes espécies, em casos de raiva transmitida por carnívoros, enquanto que os casos estudados no Brasil são, na sua maioria, transmitidos por morcegos hematófagos.

Em eqüinos, os corpúsculos de inclusão foram encontrados em somente $40 \%$ dos casos (2/5) e apareceram com menor intensidade do que em bovinos (Quadro 5). Peixoto et al. (2000) encontraram corpúsculos de inclusão em $36,9 \%$ de 111 encéfalos de cavalos examinados por esfregaços de cerebelo e corno de Ammon corados pela técnica de Sellers, enquanto que os bovinos apresentaram $79,5 \%$ de positividade. Nesse mesmo trabalho o diagnóstico de imunofluorescência deu resultados positivos em $76,6 \%$ dos eqüinos e $94,1 \%$ dos bovinos. Corpúsculos de inclusão não foram encontrados pela técnica de Faraco em esfregaços da medula espinhal, bulbo, corno de Ammon, córtex e cerebelo de dois eqüinos com raiva, enquanto que pelas técnicas de imunofluorescência e inoculação em camundongos foram positivas somente as amostras de bulbo de um eqüino $\mathrm{e}$ medula de outro, sendo negativas, para as duas provas, as amostras de corno de Ammon, córtex e cerebelo (Silva et al. 1974). Em relação à localização dos corpúsculos de Negri nas diferentes regiões do SNC, estes foram constatados somente no córtex cerebral em 2 animais e no hipocampo em um (Quadro 9). Esses fatos ressaltam a importância de examinar, tanto histologicamente quanto por imunofluorescência e inoculação de camundongos, diversas regiões do SNC para o diagnóstico da raiva em eqüinos.

A presença de corpúsculos de inclusão em caprinos e ovinos foi semelhante à observada em bovinos, já que foram observados em 83\% (5/6) dos casos; sendo o cerebelo o único local em que foram encontrados corpúsculos nos 5 animais positivos (Quadro 14), portanto, as mesmas considerações feitas para os bovinos podem ser aplicadas nos pequenos ruminantes.

No gânglio trigeminal, em bovinos, a ganglioneurite apareceu de forma acentuada em 42,8\% (6/14) dos casos, discreta em $42,8 \%(6 / 14)$ e era ausente em $14,3 \%(2 / 14)$, e corpúsculos de inclusão foram observados em somente 35\% (5/14) dos casos, sugerindo que o estudo do gânglio trigeminal é pouco importante para o diagnóstico histológico da raiva. Achados diferentes são relatados por outros autores (Jones et al. 2000), que mencionam que as lesões específicas se formam precocemente e de forma mais constante nos gânglios gasserianos do que em qualquer outro local no sistema nervoso e podem estar presentes, mesmo antes que possam ser demonstrados os corpúsculos de Negri. Os resultados deste trabalho diferem, também, dos mencionados por Coelho (2002), que relata que em bovinos, neuronofagia, satelitose pronunciada e hiperplasia neuroglial no gânglio trigeminal observam-se em 100\% dos casos de raiva.

Uma situação semelhante à dos bovinos observou-se em cavalos, nos quais, apesar do baixo número de animais estudados, somente foi observada discreta ganglioneurite em 2 dos 3 eqüinos examinados e nenhum apresentou corpúsculos de inclusão.

Em conclusão, a raiva é uma doença endêmica no semi-árido da Paraíba, afetando bovinos, ovinos, caprinos e equiinos. Em todas as espécies as lesões do SNC são difusas e os sinais clínicos variados, podendo ocorrer a forma paralítica, com lesões princi- palmente da medula, tronco encefálico e cerebelo, ou a forma furiosa ou depressiva, com lesões principalmente no cérebro. Para o diagnóstico da raiva, além de um exame clínico detalhado é necessário o estudo histológico de diversas regiões do SNC, assim como o envio de diversas regiões do SNC para realização das provas de imunofluorescência e inoculação em camundongos.

\section{REFERÊNCIAS}

Acha P.N. \& Szyfres B. 1986. Zoonosis y enfermedades transmisibles comunes al hombre y a los animales. $2^{\mathrm{a}}$ ed. Organización Panamericana de la Salud, Washington, DC., p.502-526.

Araújo F.A.A. 2002. Raiva humana no Brasil: 1992-2001. Tese de Mestrado, Escola de Veterinária, Universidade Federal de Minas Gerais, Belo Horizonte, Minas Gerais. 90p.

Bacon P.J. 1985. Population dynamics of rabies in wildlife. Academic Press, Orlando. 358p.

Barros C.S.L. 2003. Comunicação pessoal (Universidade Federal de Santa Maria, RS).

Barros J.S., Freitas C.E.A.A. \& Sousa F.S. 1989. Raiva em animais silvestres no Estado do Ceará particularmente na raposa (Dusicyon vetulus). Zoon. Rev. Int. 1(1):9-13.

Bingham J. \& Merwe M.V. 2002. Distribution of rabies antigen in infected brain material: determining the reliability of different regions of the brain for the rabies fluorescent antibody test. J. Virol. Met. 101(1-2):8594.

Braund K.G., Brewer B.D. \& Mayhew I.G. 1987. Inflamatory, infectious, imune, parasitic and vascular diseases, p.266-254 In: Oliver J.E., Horlein B.F. \& Mayhew I.G. (ed.) Veterinary Neurology. W.B. Saunders, Philadelphia.

Carlton W.W. \& McGavin M.D. 1998. Patologia Veterinária Especial de Thomson. $2^{\mathrm{a}}$ ed. ArtMed, Porto Alegre. 672p.

Coelho H.E. 2002. Patologia Veterinária. Manole, São Paulo. 234p.

Dean D.J., Abelseth M.K. \& Atanasiu P. 1996. The fluorescent antibody test, p.88-95. In: Meslin F-X., Kaplan M.M. \& Koprowski H. (ed.) Laboratory Techniques in Rabies. $4^{\mathrm{a}}$ ed. World Health Organization, Geneva.

Fernandes C.G. 2001. Raiva, p.149-162. In: Riet-Correa F., Schild A.L., Méndez M.C. \& Lemos R.A.A. (ed.) Doenças de Ruminantes e Eqüinos. Vol. 1. 2a ed. Varela, São Paulo.

Germano P.M.L., Miguel O. \& Chamelet E.L.B. 1977. Estudo comparativo entre as técnicas de coloração de Sellers, imunofluorescência direta e inoculação em camundongos, aplicadas ao diagnóstico laboratorial da raiva canina. Revta. Fac. Med. Vet. Univ. São Paulo 14(1):133-141.

Germano P.M.L., Silva E.V., Silva E.V., Miguel O. \& Sureau P. 1990. Variantes antigênicas del virus de la rabia aisladas en el Nordeste y Sudeste del Brasil. Estudio preliminar. Boletín de la Oficina Sanitaria Panamericana 108(1):39-45.

Goldwasser R.A. \& Kissling R.E. 1958. Fluorescent antibody staining of street and fixed rabies virus antigens. Proc. Soc. Exp. Biol. Med. 98:219223.

Gomes A.A.B. 2004. Epidemiologia da raiva: caracterização de vírus isolados de animais domésticos e silvestres do semi-árido paraibano da região de Patos, Nordeste do Brasil. Tese de Doutorado, Universidade de São Paulo. 107p.

Hayashi Y., Mora E., Cnandelier E.L., Montaño J.A. \& Ohi M. 1984. Estudo de proteção cruzada de 24 cepas de vírus rábico isoladas de diferentes espécies animais no Brasil. Arq. Biol. Tecnol., Curitiba, 27:27-35.

Heinemann F.M., Fernandes-Matioli F.M.C., Cortez A., Soares R.M., Sakamoto S.M., Bernardi F., Ito F.H, Madeira A.M.B.N. \& Richtzenhain L.J. 2002. Genealogical analysis of rabies virus strain from Brazil based on $\mathrm{N}$ gene alleles. Epidemiol. Infect. 128:503-511.

Hudson L.C., Weinstock D. \& Jordan T. 1996. Clinical features of experimentally induced rabies in cattle and sheep. J. Vet. Med. B 43(2):8595. 
IBGE. 2001. Efetivo do rebanho paraibano. http://www.saia.pb.gov.br/ agropecuaria/. Disponível em: 14.02.2005.

IBGE 2003. Rebanho bovino se destaca na Produção Pecuária Municipal de 2003. http://www.ibge.gov.br/home/presidencia/noticias/. Disponível em: 14.02.2005.

Jones T.C., Hunt R.D. \& King N.W. 2000. Patologia Veterinária. 6a ed. Manole, São Paulo. 1415p.

Jubb K.V.F. \& Huxtable C.R. 1993. The nervous system, p.267-439. In: Jubb K.V.F., Kennedy P.C. \& Palmer N. (ed.) Pathology of Domestic Animals. Vol. 1. $4^{\text {a }}$ ed. Academic Press, San Diego.

King A.A. \& Turner G.S. 1993. Rabies: a review. J. Comp. Path. 108(1):1-39.

Koprowski H.T. 1996. The mouse inoculation, p.80-87. In: Meslin F.X., Kaplan M.M. \& Koprowski H. (ed.) Laboratory Techniques in Rabies. $4^{\text {th }}$ ed. World Health Organization, Geneva.

Langohr I.M., Irigoyen L.F., Lemos R.A.A. \& Barros C.S.L. 2003. Aspectos epidemiológicos e clínicos e distribuição das lesões histológicas no encéfalo de bovinos com raiva. Ciência Rural, Santa Maria, 33(1):125-131.

Lemos R.A.A. 2005. Enfermidades do sistema nervoso de bovinos de corte das regiões centro-oeste e sudeste do Brasil. Tese de Doutorado, Universidade Estadual Paulista, Jaboticabal. 155p.

Lima E.F., Riet-Correa F., Tabosa I.M., Dantas J.M., Medeiros J.M. \& Sucupira Junior G. 2005. Polioencefalomalacia em caprinos e ovinos na região semi-árida do nordeste do Brasil. Pesq. Vet. Bras. 25:9-14.

Macruz R., Nilsson M.R. \& Côrtes J.A. 1977. Raiva experimental em bovinos: histopatologia do sistema nervoso central. Revta Fac. Med. Vet. Zootec., São Paulo, 14(1):123-127.

Montaño J.A., Polack G.W. \& Mora E.F. 1987. Raiva bovina em animais vacinados. II. Situação epidemiológica no estado do Paraná, Brazil, 1984. Arq. Biol. Tecnol., Curitiba, 30:367-380.

Morais N.B., Rolim B.N., Chaves H.H.M., Brito-Neto J. \& Silva L.M. 2000. Rabies in tamarins (Callithrix jacchus) in the State of Ceará, Brazil, a distinct viral variant? Mem. Inst. Osw. Cruz 95(5):609-610.

Mori A.E., Lemos R.A.A. \& Kadri A. 2004. Raiva, p.63-86. In: Lemos R.A.A. (Organizador). Série Qualificação Rural 2:63-86.

Nobre V.M.T., Riet-Correa F., Barbosa Filho J.M., Tabosa I.M. \& Vasconcelos J.S. 2004a. Intoxicação por Crotalaria retusa (Fabaceae) em eqüídeos no semi-árido da Paraíba. Pesq. Vet. Bras. 24 (3):132-143.

Organización Pan-Americana de la Salud (Rio de Janeiro). 2001. Boln 33, Vigilância epidemiológica de la rabia en las Américas. 40p.

Peixoto Z.M.P., Cunha E.M.S., Sacramento D.R.V., Conceição M., Souza A.M., da Silva L.H.Q., Germano P.L., Kroeff S.S. \& Kotait I. 2000. Rabies laboratory diagnosis: peculiar features of samples from equine origen. Braz. J. Microbiol. 31 (1):72-75.

Radostits O.M., Blood D.C., Gay C.C. \& Hinchcliff D.C. 2002. Clínica Vete- rinária: um tratado de doenças dos bovinos, ovinos, suínos, caprinos e eqüinos. $9^{\text {a }}$ ed. Guanabara Koogan, Rio de Janeiro. 1737p.

Rede Interagencial de Informação para a Saúde (Brasília) 2002. Indicadores básicos de saúde no Brasil: conceitos e aplicações. Organização PanAmericana de Saúde, DF, Brasil, p.150-151.

Riet-Correa F., Schild A.L., Méndez M.C., Oliveira J.A., Gil-Turnes C. \& Gonçalves A. 1983. Relatório das atividades e doenças da área de influência no período de 1978-1982. Laboratório Regional de Diagnóstico. Editora e Gráfica Universitária, Pelotas. 98p.

Riet-Correa F., Ferreira J. L.M. \& Schild A.L. 1999. Relatório das atividades e doenças da área de influência no período de 1978-1982. Laboratório Regional de Diagnóstico. Editora e Gráfica Universitária, Pelotas. 43p.

Riet-Correa F., Riet-Correa G. \& Schild A.L. 2002. Importância do exame clínico para o diagnóstico das enfermidades do sistema nervoso em ruminantes e eqüídeos. Pesq. Vet. Bras. 22(4):161-168.

Riet-Correa F., Tabosa I.M., Azevedo E.O., Medeiros R.M.T., Simões S.V.D., Dantas A.A., Alves C.J., Nobre V.M.T., Athayde A.C. \& Lima, E.F. 2003. Doenças dos ruminantes e eqüinos no semi-árido da Paraíba. Semi-Árido em Foco, Patos, 1:2-86.

Rodrigues da Silva A.D.C., Caporale G.M.M., Gonçalves C.A., Targueta M.C., Comin F., Zanetti C.R. \& Kotait I. 2000. Antibody response in cattle after vaccination with inactivated and attenuated rabies vaccines. Revta Inst. Med. Trop., São Paulo, 42:95-98.

Rondon E.S., Bastos P.V., Silva D.A. \& Piccinini R.S. 1995. Estudo comparativo da sintomatologia clínica de bovinos suspeitos de raiva. Revta Bras. Med. Vet. 17(6):253-256.

Sanches A.W.D., Langohr I.M., Stigge A.L. \& Barros C.S.L. 2000. Doenças do sistema nervoso central em bovinos no sul do Brasil. Pesq. Vet. Bras. 20(3):113-118

Silva R.A., Silva N.M. \& Meneses P.R.V. 1974. Ocorrência do vírus da raiva na medula e bulbo de eqüinos na doença natural e sua ausência nas diferentes regiões do sistema nervosos central e outros tecidos. Pesq. Agropeq. Bras., Sér.Vet., 9:29-31.

Silva J.A., Moreira E.C., Haddad J.P.A., Modena C.M. \& Tubaldini M.A.S. 2001. Distribuição temporal e espacial da raiva bovina em Minas Gerais, 1976-1977. Arq. Bras. Med. Vet. Zootec. 53(3)263-272.

Summers B.A., Cummings J.F. \& de Lahunta A. 1995. Veterinary Neuropathology. Mosby, Baltimore. 527p.

Swanepoel R. 1994. Rabies, p.392-400. In: Coetzer J.A.W., Thomson F.R. \& Tustin R.C. (ed.) Infections Diseases of Livestock, with special reference to Southern Africa. Vol.1. Oxford University Press, Cape Town.

Tierkel E.S. 1975. Canine rabies, p.123-137. In: Baer G.M. (ed.) The Natural History of Rabies. Vol 2. Academic Press, New York.

Zimmer K., Wiegand D. \& Manz D. 1990. Evaluation of five different methods for routine diagnosis of rabies. J. Vet. Med. B 37(5):392-400. 